\title{
Article \\ Proteomic Profiling of BRAFV600E Mutant Colon Cancer Cells Reveals the Involvement of Nucleophosmin/c-Myc Axis in Modulating the Response and Resistance to BRAF Inhibition by Vemurafenib
}

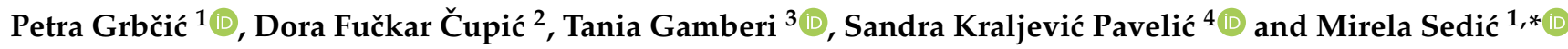 \\ 1 Department of Biotechnology, University of Rijeka, Radmile Matejčić 2, 51000 Rijeka, Croatia; \\ petra.grbcic@biotech.uniri.hr \\ 2 Faculty of Medicine, University of Rijeka, Ul. Braće Branchetta 20/1, 51000 Rijeka, Croatia; \\ dorica9@gmail.com \\ 3 Dipartimento di Scienze Biomediche, Sperimentali e Cliniche Mario Serio, University of Florence, \\ Viale Morgagni 50, 50134 Florence, Italy; tania.gamberi@unifi.it \\ 4 Faculty of Health Studies, University of Rijeka, Viktora Cara Emina 5, 51000 Rijeka, Croatia; \\ sandrakp@uniri.hr \\ * Correspondence: msedic@biotech.uniri.hr; Tel.: +385-51-584-574
}

Citation: Grbčić, P.; Fučkar Čupić, D.; Gamberi, T.; Kraljević Pavelić, S.; Sedić, M. Proteomic Profiling of BRAFV600E Mutant Colon Cancer Cells Reveals the Involvement of Nucleophosmin/c-Myc Axis in Modulating the Response and Resistance to BRAF Inhibition by Vemurafenib. Int. J. Mol. Sci. 2021, 22, 6174. https://doi.org/10.3390/ ijms22126174

Academic Editor: Girolamo Ranieri

Received: 20 April 2021

Accepted: 3 June 2021

Published: 8 June 2021

Publisher's Note: MDPI stays neutral with regard to jurisdictional claims in published maps and institutional affiliations.

Copyright: (c) 2021 by the authors. Licensee MDPI, Basel, Switzerland. This article is an open access article distributed under the terms and conditions of the Creative Commons Attribution (CC BY) license (https:/ / creativecommons.org/licenses/by/ $4.0 /)$.

\begin{abstract}
BRAFV600E mutations are found in approximately $10 \%$ of colorectal cancer patients and are associated with worse prognosis and poor outcomes with systemic therapies. The aim of this study was to identify novel druggable features of BRAFV600E-mutated colon cancer (CC) cells associated with the response and resistance to BRAFV600E inhibitor vemurafenib. Towards this aim, we carried out global proteomic profiling of BRAFV600E mutant vs. KRAS mutant/BRAF wild-type and double wild-type KRAS/BRAF CC cells followed by bioinformatics analyses. Validation of selected proteomic features was performed by immunohistochemistry and in silico using the TCGA database. We reveal an increased abundance and activity of nucleophosmin (NPM1) in BRAFV600E-mutated $\mathrm{CC}$ in vitro, in silico and in tumor tissues from colon adenocarcinoma patients and demonstrate the roles of NPM1 and its interaction partner c-Myc in conveying the resistance to vemurafenib. Pharmacological inhibition of NPM1 effectively restored the sensitivity of vemurafenib-resistant BRAF-mutated CC cells by down-regulating c-Myc expression and activity and consequently suppressing its transcriptional targets RanBP1 and phosphoserine phosphatase that regulate centrosome duplication and serine biosynthesis, respectively. Altogether, findings from this study suggest that the NPM1/c-Myc axis could represent a promising therapeutic target to thwart resistance to vemurafenib in BRAF-mutated CC.
\end{abstract}

Keywords: colorectal cancer; BRAFV600E mutation; vemurafenib; PLX4032; chemoresistance; nucleophosmin; c-Myc; proteomic; bioinformatics

\section{Introduction}

BRAFV600E mutations are found in approximately $10 \%$ of colorectal cancer (CRC) patients and are associated with sustained cell proliferation, diminished apoptosis and acquired resistance to standard and targeted chemotherapies [1]. In CRC, the BRAFV600E mutation confers worse prognosis, decreased overall survival and poor outcomes with systemic therapies. In general, BRAFV600E mutant CRC exerts distinctive molecular, pathological and clinical features. Specifically, the BRAFV600E mutation is commonly associated with the serrated adenoma pathway, right-sided CRC, T4 stage, poor differentiation and mucinous histology and is prevalent in elderly female patients [2]. In addition, tumors bearing a BRAF mutation often show microsatellite instability (MSI), hypermethylation, higher incidence of $\mathrm{CPG}$ island methylation and distinct patterns of metastasis characterized mainly by peritoneal and nodal metastases and, less likely, lung metastases. 
Although treatment with single-agent BRAFV600E inhibitor vemurafenib (PLX4032) resulted in promising response rates in metastatic melanoma patients harboring the BRAFV600E mutation, clinically meaningful activity was not achieved in BRAF mutant metastatic CRC patients, which implies that the BRAFV600E-regulated response and resistance to therapy mirror tissue- and cancer-type specific biological contexts defined by the BRAFV600E mutation. The heterogeneous clinical response to targeted therapies observed in BRAFV600E mutant CRC patients has spurred investigation into the molecular basis underlying these differences, which has led to the discovery of two gene expression-based subgroups of BRAFV600E-mutated CRC, one exerting KRAS/AKT pathway activation, mTOR/4EBP deregulation and epithelial-mesenchymal transition (EMT), and the other showing dysregulation of the cell cycle [3]. Expectedly, the same study indicated that these two subtypes have different sensitivities in silico to targeted chemotherapy drugs including BRAF and MEK inhibitors, reflecting their observed molecular differences.

The functional consequences of the BRAFV600E mutation in CRC and its impact on molecular processes that govern cell behavior and response to chemotherapy have not been fully elucidated. Several efforts have been made to investigate the underlying biological context of the BRAFV600E mutation in CRC by capturing specific changes in the gene expression levels that could distinguish tumors bearing the BRAFV600E mutation from other oncogenic mutations and molecular types of CRC [4-7]. The distinctive gene expression signature of BRAFV600E mutant CRC could serve as a classification and prognostic tool and could also reveal novel therapeutic vulnerabilities of BRAF mutant CRC, which would enable the development of tailored treatment for CRC patients with the BRAFV600E mutation. Based on the genes that were specifically up-regulated in BRAF mutant CRC in comparison with BRAF and KRAS wild-type CRC, Vecchione et al. [6] were able to identify spindle formation and mitotic progression as distinct druggable features of BRAFV600E mutant colon cancer cells and revealed the ability of vinorelbine, a vinca alkaloid that prevents formation of the mitotic spindle, to selectively suppress the growth of BRAF-mutated colon cancer cells both in vitro and in vivo. Another example showing the utility of the BRAFV600E mutant-specific gene expression signature as a target for novel candidate therapy in CRC was provided by San Lucas et al. [8], who employed an in silico approach to reveal specific gene expression signatures of BRAFV600E mutant CRC as compared to BRAF wild-type CRC and identified EGFR inhibitor gefitinib and proteasome inhibitor MG-262 as potential candidate drugs to specifically treat BRAFV600E CRC.

In the present study, we set out to explore global proteomic features of BRAFV600E mutant colon cancer cells in comparison with KRAS mutant/BRAF wild-type and double wild-type KRAS/BRAF colon cancer cells in order to identify novel druggable vulnerabilities of BRAF-mutated colon cancer that could play a role in regulating the cell response and resistance to BRAFV600E inhibition by vemurafenib. Bioinformatics analysis of proteins specifically up-regulated in BRAF-mutated cells revealed several cellular events that could be potentially associated with the BRAFV600E mutation in colon cancer cells including cytoskeleton remodeling, cell-cell adhesion, transcriptional and epigenetic dysregulations, increased ribosome biogenesis and protein synthesis, positive regulation of the cell cycle, centrosome cycle and mitosis, mitochondrial biogenesis and metabolic alterations linked with increased activity of the enzymes regulating methionine and serine biosynthesis. Importantly, our study reveals an increased abundance and activity of nucleophosmin (NPM1) that could be linked with initiation of centrosome amplification and mitosis as a novel molecular trait of BRAFV600E-mutated colon cancer in vitro, in silico and in tumor tissues from colon adenocarcinoma patients and provides evidence to demonstrate the roles of NPM1 and its interaction partner c-Myc in conveying the resistance to BRAF inhibitor vemurafenib. Pharmacological inhibition of NPM1 was proved effective in restoring the sensitivity of vemurafenib-resistant colon cancer cells with the BRAFV600E mutation by mechanisms that include down-regulation of c-Myc expression and activity and consequent suppression of its transcriptional targets RanBP1 and phosphoserine phosphatase regulating centrosome duplication and serine biosynthesis, respectively. Collectively, find- 
ings from this study provide ample indication that the NPM1/c-Myc axis could represent a promising therapeutic target to thwart resistance to vemurafenib in BRAF-mutated colon cancer.

\section{Results}

\subsection{Proteomic Profiling of Colon Cancer Cell Lines Differing in BRAF Mutation Status}

In order to identify proteomic features specifically associated with the BRAFV600E mutation in colon cancer and to exclude, at the same time, the possible interference resulting from the genetic diversity of different cell lines, we performed comparative proteomic profiling of the three selected colon cancer cell lines having the same MSI status, wt PTEN, wt PIK3CA and mutated $p 53$, and differing only in BRAF/KRAS mutational status as follows: HT-29 (BRAFV600E/KRASwt), SW480 (BRAFwt/KRASG12V) and Caco-2 (BRAFwt/KRASwt).

Towards this aim, total cell proteins were resolved by two-dimensional polyacrylamide gel electrophoresis (2-DE) (Figure 1) followed by gel image analysis that enabled the detection of a total of 950 protein spots.
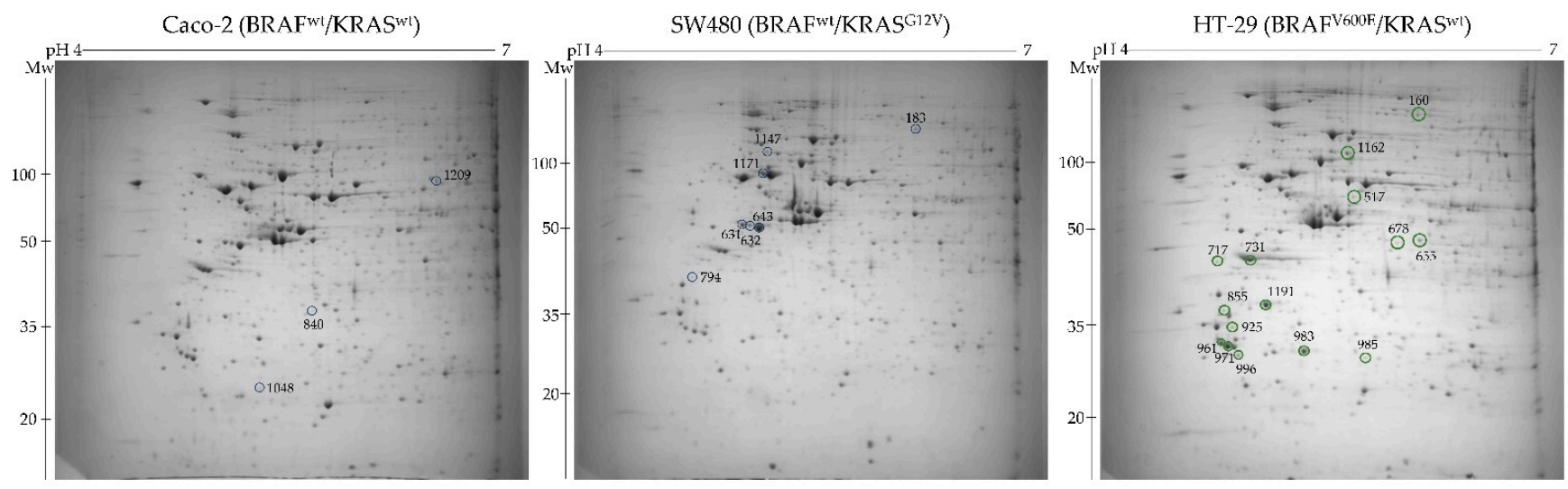

Figure 1. Representative 2-DE gel images of total cell proteome obtained in the $\mathrm{pH}$ range 4-7 from the three colon cancer cell lines differing in BRAF mutational status. Marked with a green circle are up-regulated protein spots detected in BRAFV600E mutant cells, while blue circles designate down-regulated protein spots.

Among these, 166 spots were differentially expressed with a statistical significance (ANOVA $p$-value $<0.05$ ) between the three cell lines, from which 16 and 10 were upand down-regulated, respectively, specifically in the cell line harboring the BRAFV600E mutation in comparison to the cell lines carrying wild-type BRAF. These protein spots were manually excised, and their identity was revealed by MALDI-TOF/TOF mass spectrometry. Lists of differentially abundant protein spots between BRAF-mutated and BRAF WT cell lines are given in Tables 1 and 2.

\subsection{Bioinformatics Analysis of Proteomic Data}

\subsubsection{Functional and Pathway Enrichment Analysis}

In an attempt to better understand a molecular and cellular context in which the identified up-regulated proteins function, we performed bioinformatics analysis using several publicly available tools. First, we investigated biological functions of up-regulated proteins using the DAVID database for Gene Ontology functional annotation. The three GO categories, namely, cellular component (CC), biological process (BP) and molecular function (MF), were detected using DAVID. The top GO terms for differentially expressed proteins with increased abundance in the BRAFV600E cell line are shown in Supplementary Tables S1-S3. 
Table 1. List of differentially up-regulated proteins with statistical significance $(p<0.05)$ in BRAFV600E mutant HT-29 cells in comparison to Caco-2 and SW480 colon cancer cells.

\begin{tabular}{|c|c|c|c|c|c|c|}
\hline $\begin{array}{c}\text { Spot } \\
\text { Number }\end{array}$ & Accession ID & $\begin{array}{c}\text { Protein Name } \\
\quad p \text {-Value } \\
\text { (HT-29 vs. Caco-2; } \\
\text { HT-29 vs. SW480) }\end{array}$ & $\begin{array}{c}\text { Molecular } \\
\text { Weight (kDa) }\end{array}$ & $\begin{array}{l}\text { Peptide } \\
\text { Matches }\end{array}$ & $\begin{array}{c}\text { Sequence } \\
\text { Coverage }(\%)\end{array}$ & SCORE \\
\hline 160 & MIC60_HUMAN & $\begin{array}{l}\text { MICOS complex } \\
\text { subunit MIC60 } \\
(0.002 ; 0.044)\end{array}$ & 83.60 & 4 & 10.00 & 307.41 \\
\hline 517 & K1C20_HUMAN & $\begin{array}{l}\text { Keratin, type I cytoskeletal } 20 \\
\qquad(0.001 ; 0.001)\end{array}$ & 48.50 & 4 & 9.90 & 145.21 \\
\hline 678 & ROAA_HUMAN & $\begin{array}{l}\text { Heterogeneous nuclear } \\
\text { ribonucleoprotein A/B } \\
\qquad(0.010 ; 0.011)\end{array}$ & 36.20 & 2 & 3.90 & 60.25 \\
\hline 731 & NPM_HUMAN & $\begin{array}{l}\text { Nucleophosmin } \\
(0.028 ; 0.016)\end{array}$ & 32.60 & 4 & 16.30 & 191.18 \\
\hline 717 & K2C1_HUMAN & $\begin{array}{l}\text { Keratin, type II cytoskeletal } 1 \\
(0.009 ; 0.003)\end{array}$ & 66.00 & 1 & 2.50 & 44.11 \\
\hline 925 & TPM1_HUMAN & $\begin{array}{l}\text { Tropomyosin alpha-1 chain } \\
\qquad(0.030 ; 0.001)\end{array}$ & 32.70 & 2 & 8.80 & 79.33 \\
\hline 983 & RANG_HUMAN & $\begin{array}{c}\text { Ran-specific } \\
\text { GTPase-activating protein } \\
(0.001 ; 0.0003)\end{array}$ & 23.47 & 16 & 47.00 & 76.00 \\
\hline 996 & UCHL3_HUMAN & $\begin{array}{l}\text { Ubiquitin carboxyl-terminal } \\
\text { hydrolase isozyme L3 } \\
(0.039 ; 0.023)\end{array}$ & 26.34 & 18 & 70.00 & 178.00 \\
\hline 1191 & ARI5B_HUMAN & $\begin{array}{c}\text { AT-rich interactive } \\
\text { domain-containing protein 5B } \\
(0.006 ; 0.002)\end{array}$ & 133.43 & 14 & 17.00 & 37.00 \\
\hline 985 & $\begin{array}{l}\text { MIXTURE } 1 \\
\text { SERB_HUMAN } \\
\text { IF4E_HUMAN }\end{array}$ & $\begin{array}{c}\text { Phosphoserine phosphatase } \\
\text { Eukaryotic translation } \\
\text { initiation factor } 4 \mathrm{E} \\
(0.040 ; 0.030)\end{array}$ & $\begin{array}{l}25.16 \\
25.31\end{array}$ & $\begin{array}{l}16 \\
14\end{array}$ & $\begin{array}{l}62.00 \\
48.00\end{array}$ & $\begin{array}{c}100.00 \\
85.00\end{array}$ \\
\hline 961 & $\begin{array}{l}\text { YWHAZ } \\
\text { _HUMAN }\end{array}$ & $\begin{array}{l}\text { 14-3-3 protein theta } \\
(0.043 ; 0.061)\end{array}$ & 28.032 & 13 & 40.00 & 53.00 \\
\hline 1162 & NMES1_HUMAN & $\begin{array}{l}\text { Normal mucosa of } \\
\text { oesophagus-specific } \\
\text { gene } 1 \text { protein } \\
(0.005 ; 0.004)\end{array}$ & 9.611 & 4 & 55.00 & 37.00 \\
\hline 855 & ENOPH_HUMAN & $\begin{array}{c}\text { Enolase-phosphatase E1 } \\
(0.027 ; 0.0978)\end{array}$ & 28.90 & 6 & 34.10 & 378.18 \\
\hline 971 & YWHAQ_HUMAN & $\begin{array}{c}14-3-3 \text { protein zeta / delta } \\
(0.073 ; 0.043)\end{array}$ & 27.899 & 21 & 38.00 & 114 \\
\hline 655 & CAPG_HUMAN & $\begin{array}{l}\text { Macrophage-capping protein } \\
(0.0003 ; 0.077)\end{array}$ & 38.50 & 4 & 10.30 & 223.83 \\
\hline
\end{tabular}

The cellular component (CC) analysis revealed that up-regulated proteins were mostly localized to the intracellular part, cytoskeleton and adherens junction, as well as to the extracellular part (exosomes and vesicles) (Supplementary Table S1). For biological process (BP), up-regulated proteins were mainly enriched in organelle organization, regulation of cytoskeleton organization, mitochondrial membrane organization, cell-cell adhesion, positive regulation of the cell cycle (namely, G1/S phase transition) and centrosome cycle and intracellular transport including RNA export from the nucleus (Supplementary Table S2). 
Up-regulated proteins in the molecular function category were significantly associated with poly(A) RNA binding, cadherin binding and protein binding involved in cell-cell adhesion (Supplementary Table S3).

Table 2. List of differentially down-regulated proteins with statistical significance $(p<0.05)$ in BRAFV600E mutant HT-29 cells in comparison to Caco-2 and SW480 colon cancer cells.

\begin{tabular}{|c|c|c|c|c|c|c|}
\hline $\begin{array}{c}\text { Spot } \\
\text { Number }\end{array}$ & Accession ID & $\begin{array}{c}\text { Protein Name } \\
p \text {-Value } \\
\text { (HT-29 vs. Caco-2; } \\
\text { HT-29 vs. SW480) }\end{array}$ & $\begin{array}{c}\text { Molecular } \\
\text { Weight (kDa) }\end{array}$ & $\begin{array}{l}\text { Peptide } \\
\text { Matches }\end{array}$ & $\begin{array}{c}\text { Sequence } \\
\text { Coverage }(\%)\end{array}$ & SCORE \\
\hline 183 & MOES_HUMAN & $\begin{array}{c}\text { Moesin } \\
(0.001 ; 0.005)\end{array}$ & 67.80 & 3 & 3.50 & 119.80 \\
\hline 631 & K1C19_HUMAN & $\begin{array}{l}\text { Keratin, type I cytoskeletal } 19 \\
\quad(<0.0001 ;<0.0001)\end{array}$ & 44.10 & 2 & 7.80 & 142.88 \\
\hline 643 & K1C19_HUMAN & $\begin{array}{l}\text { Keratin, type I cytoskeletal } 19 \\
(<0.0001 ;<0.0001)\end{array}$ & 44.10 & 9 & 27.30 & 527.99 \\
\hline 632 & K1C19_HUMAN & $\begin{array}{l}\text { Keratin, type I cytoskeletal } 19 \\
(<0.0001 ;<0.0001)\end{array}$ & 44.10 & 11 & 36.00 & 856.99 \\
\hline 840 & ANXA3_HUMAN & $\begin{array}{c}\text { Annexin A3 } \\
(0.0001 ; 0.0002)\end{array}$ & 36.40 & 2 & 13.90 & 149.55 \\
\hline 1048 & PCNA_HUMAN & $\begin{array}{c}\text { Proliferating cell } \\
\text { nuclear antigen } \\
(0.016 ; 0.002)\end{array}$ & 29.09 & 13 & 59.00 & 97.00 \\
\hline 1171 & $\begin{array}{c}\text { MIXTURE } 1 \\
\text { DBNL_HUMAN } \\
\text { TBA1B_HUMAN }\end{array}$ & $\begin{array}{l}\text { Drebrin-like protein } \\
\text { Tubulin alpha-1B chain } \\
\quad(0.034 ; 0.001)\end{array}$ & $\begin{array}{l}48.46 \\
50.80\end{array}$ & $\begin{array}{l}17 \\
16\end{array}$ & $\begin{array}{l}34.00 \\
39.00\end{array}$ & $\begin{array}{l}88.00 \\
86.00\end{array}$ \\
\hline 1209 & T191A_HUMAN & $\begin{array}{l}\text { Transmembrane protein } 191 \mathrm{~A} \\
(0.001 ; 0.014)\end{array}$ & 18.06 & 4 & 33.00 & 30.00 \\
\hline 1147 & EPHA6_HUMAN & $\begin{array}{c}\text { Ephrin type-A receptor } 6 \\
(0.0772 ;<0.0001)\end{array}$ & 117.901 & 8 & 13.00 & 40 \\
\hline 794 & HSP7C_HUMAN & $\begin{array}{l}\text { Heat shock cognate } \\
71 \mathrm{kDa} \text { protein } \\
(0.026 ; 0.131)\end{array}$ & 70.90 & 3 & 7.60 & 214.36 \\
\hline
\end{tabular}

Next, we carried out pathway enrichment analysis based on the input from the upregulated proteomic dataset using the Reactome database, where $p<0.05$ was considered a threshold value. This analysis revealed 33 pathways with statistical significance in which up-regulated proteins seem to be involved (Table 3). The pathways related to the cell cycle, G2/M checkpoints, condensation of prometaphase chromosomes and G2/M DNA damage checkpoint are associated with the modulation of the mechanisms that regulate the cell cycle and progression through mitosis. Interestingly, Reactome analysis also showed significant enrichment for the pathway associated with epigenetic mechanisms. These include demethylation of histones by histone demethylases (HDMs) that generates formaldehyde, which is transferred to homocysteine to generate methionine, which is then cycled back to S-adenosylmethionine (SAM), a methyl group donor in many important transfer reactions including DNA methylation. SAM may also be used to regenerate methionine in the methionine salvage pathway, and the latter was also identified by Reactome analysis (Table 3). Another metabolic alteration potentially linked with the BRAFV600E mutation as revealed by Reactome analysis appears to include serine biosynthesis. 
Table 3. Pathway enrichment analysis of up-regulated proteins in BRAFV600E mutant HT-29 colon cancer cells using the Reactome Pathway Database.

\begin{tabular}{|c|c|c|c|c|c|c|}
\hline Pathway Identifier & Pathway Name & $\begin{array}{l}\text { \#Entities } \\
\text { Found }\end{array}$ & $\begin{array}{c}\text { \#Entities } \\
\text { Total }\end{array}$ & $\begin{array}{l}\text { Entities } \\
p \text {-Value }\end{array}$ & Entities FDR & $\begin{array}{c}\text { Submitted } \\
\text { Entities Found }\end{array}$ \\
\hline R-HSA-9614399 & $\begin{array}{l}\text { Regulation of localization } \\
\text { of FOXO } \\
\text { transcription factors }\end{array}$ & 2 & 12 & $1.44 \times 10^{-4}$ & 0.009 & $\begin{array}{l}\text { YWHAQ; } \\
\text { YWHAZ }\end{array}$ \\
\hline R-HSA-75035 & $\begin{array}{l}\text { Chk1/Chk2(Cds1) } \\
\text { mediated inactivation of } \\
\text { Cyclin B: Cdk1 complex }\end{array}$ & 2 & 13 & $1.69 \times 10^{-4}$ & 0.009 & $\begin{array}{l}\text { YWHAQ; } \\
\text { YWHAZ }\end{array}$ \\
\hline R-HSA-111447 & $\begin{array}{l}\text { Activation of BAD and } \\
\text { translocation to } \\
\text { mitochondria }\end{array}$ & 2 & 15 & $2.25 \times 10^{-4}$ & 0.009 & $\begin{array}{l}\text { YWHAQ; } \\
\text { YWHAZ }\end{array}$ \\
\hline R-HSA-114452 & $\begin{array}{l}\text { Activation of } \mathrm{BH} 3- \\
\text { only proteins }\end{array}$ & 2 & 30 & $8.88 \times 10^{-4}$ & 0.026 & $\begin{array}{l}\text { YWHAQ; } \\
\text { YWHAZ }\end{array}$ \\
\hline R-HSA-390522 & $\begin{array}{l}\text { Striated Muscle } \\
\text { Contraction }\end{array}$ & 2 & 36 & 0.001 & 0.028 & TPM1 \\
\hline R-HSA-445355 & $\begin{array}{l}\text { Smooth Muscle } \\
\text { Contraction }\end{array}$ & 2 & 39 & 0.001 & 0.028 & TPM1 \\
\hline R-HSA-109606 & $\begin{array}{l}\text { Intrinsic Pathway } \\
\text { for Apoptosis }\end{array}$ & 2 & 55 & 0.003 & 0.041 & $\begin{array}{l}\text { YWHAQ; } \\
\text { YWHAZ }\end{array}$ \\
\hline R-HSA-5625740 & $\begin{array}{l}\text { RHO GTPases } \\
\text { activate PKNs }\end{array}$ & 2 & 63 & 0.004 & 0.046 & $\begin{array}{l}\text { YWHAQ; } \\
\text { YWHAZ }\end{array}$ \\
\hline R-HSA-9614085 & $\begin{array}{l}\text { FOXO-mediated } \\
\text { transcription }\end{array}$ & 2 & 66 & 0.004 & 0.046 & $\begin{array}{l}\text { YWHAQ; } \\
\text { YWHAZ }\end{array}$ \\
\hline R-HSA-1445148 & $\begin{array}{c}\text { Translocation of SLC2A4 } \\
\text { (GLUT4) to the } \\
\text { plasma membrane }\end{array}$ & 2 & 72 & 0.005 & 0.049 & $\begin{array}{l}\text { YWHAQ; } \\
\text { YWHAZ }\end{array}$ \\
\hline R-HSA-69473 & $\begin{array}{l}\text { G2/M DNA damage } \\
\text { checkpoint }\end{array}$ & 2 & 78 & 0.006 & 0.059 & $\begin{array}{l}\text { YWHAQ; } \\
\text { YWHAZ }\end{array}$ \\
\hline R-HSA-5628897 & $\begin{array}{l}\text { TP53 Regulates } \\
\text { Metabolic Genes }\end{array}$ & 2 & 88 & 0.007 & 0.059 & $\begin{array}{l}\text { YWHAQ; } \\
\text { YWHAZ }\end{array}$ \\
\hline R-HSA-8869496 & $\begin{array}{c}\text { TFAP2A acts as a } \\
\text { transcriptional repressor } \\
\text { during retinoic acid } \\
\text { induced cell } \\
\text { differentiation }\end{array}$ & 1 & 5 & 0.007 & 0.059 & NPM1 \\
\hline R-HSA-1237112 & $\begin{array}{l}\text { Methionine salvage } \\
\text { pathway }\end{array}$ & 1 & 6 & 0.009 & 0.061 & ENOPH1 \\
\hline R-HSA-977347 & Serine biosynthesis & 1 & 9 & 0.013 & 0.078 & PSPH \\
\hline R-HSA-1640170 & Cell Cycle & 4 & 670 & 0.015 & 0.078 & $\begin{array}{l}\text { NPM1; } \\
\text { YWHAQ; } \\
\text { CAPG; } \\
\text { YWHAZ }\end{array}$ \\
\hline R-HSA-3700989 & $\begin{array}{c}\text { Transcriptional } \\
\text { Regulation by TP53 }\end{array}$ & 3 & 367 & 0.016 & 0.078 & $\begin{array}{l}\text { NPM1; } \\
\text { YWHAQ; } \\
\text { YWHAZ }\end{array}$ \\
\hline R-HSA-2514853 & $\begin{array}{l}\text { Condensation of } \\
\text { Prometaphase } \\
\text { Chromosomes }\end{array}$ & 1 & 11 & 0.016 & 0.078 & CAPG \\
\hline
\end{tabular}


Table 3. Cont.

\begin{tabular}{|c|c|c|c|c|c|c|}
\hline Pathway Identifier & Pathway Name & $\begin{array}{l}\text { \#Entities } \\
\text { Found }\end{array}$ & $\begin{array}{l}\text { \#Entities } \\
\text { Total }\end{array}$ & $\begin{array}{l}\text { Entities } \\
p \text {-Value }\end{array}$ & Entities FDR & $\begin{array}{c}\text { Submitted } \\
\text { Entities Found }\end{array}$ \\
\hline R-HSA-9013700 & $\begin{array}{l}\text { NOTCH4 Activation and } \\
\text { Transmission of Signal to } \\
\text { the Nucleus }\end{array}$ & 1 & 11 & 0.016 & 0.078 & YWHAZ \\
\hline R-HSA-69481 & G2/M Checkpoints & 2 & 151 & 0.020 & 0.078 & $\begin{array}{l}\text { YWHAQ; } \\
\text { YWHAZ }\end{array}$ \\
\hline R-HSA-392517 & Rap1 signaling & 1 & 16 & 0.023 & 0.078 & YWHAZ \\
\hline R-HSA-450604 & $\begin{array}{l}\text { KSRP (KHSRP) binds and } \\
\text { destabilizes mRNA }\end{array}$ & 1 & 17 & 0.025 & 0.078 & YWHAZ \\
\hline R-HSA-109581 & Apoptosis & 2 & 182 & 0.029 & 0.078 & $\begin{array}{l}\text { YWHAQ; } \\
\text { YWHAZ }\end{array}$ \\
\hline R-HSA-6804115 & $\begin{array}{l}\text { TP53 regulates } \\
\text { transcription of additional } \\
\text { cell cycle genes whose } \\
\text { exact role in the p53 } \\
\text { pathway remain uncertain }\end{array}$ & 1 & 21 & 0.030 & 0.078 & NPM1 \\
\hline R-HSA-397014 & Muscle contraction & 2 & 196 & 0.033 & 0.078 & TPM1 \\
\hline R-HSA-166208 & $\begin{array}{l}\text { mTORC1-mediated } \\
\text { signaling }\end{array}$ & 1 & 24 & 0.035 & 0.078 & EIF4E \\
\hline R-HSA-429947 & Deadenylation of mRNA & 1 & 25 & 0.036 & 0.078 & EIF4E \\
\hline R-HSA-3214842 & $\begin{array}{l}\text { HDMs demethylate } \\
\text { histones }\end{array}$ & 1 & 26 & 0.037 & 0.078 & ARID5B \\
\hline R-HSA-5357801 & Programmed Cell Death & 2 & 217 & 0.040 & 0.078 & $\begin{array}{l}\text { YWHAQ; } \\
\text { YWHAZ }\end{array}$ \\
\hline R-HSA-1614635 & $\begin{array}{l}\text { Sulfur amino acid } \\
\text { metabolism }\end{array}$ & 1 & 28 & 0.040 & 0.078 & ENOPH1 \\
\hline R-HSA-8866652 & $\begin{array}{c}\text { Synthesis of active } \\
\text { ubiquitin: roles of E1 and } \\
\text { E2 enzymes }\end{array}$ & 1 & 30 & 0.043 & 0.078 & UCHL3 \\
\hline R-HSA-8949613 & Cristae formation & 1 & 31 & 0.045 & 0.078 & IMMT \\
\hline R-HSA-9013424 & RHOV GTPase cycle & 1 & 33 & 0.047 & 0.078 & TPM1 \\
\hline
\end{tabular}

Given that metabolism of serine and methionine is intimately linked with the activation of mTOR signaling $[9,10]$, it is no surprise that the component of this signaling pathway, namely, mTORC1, which is the major effector of the PI3K-AKT pathway, also emerged from the Reactome analysis. mTOR has been previously identified as a potential therapeutic target in BRAFV600E-driven colorectal cancer [11]. In particular, the PI3K/mTOR pathway was shown to be one of the mechanisms underlying the resistance of BRAFV600E colon cancer cells to BRAF inhibition that could be overcome by concurrent BRAF and PI3K/mTOR blockade [12].

\subsubsection{PPI Network Construction and Module Analysis}

In order to predict and analyze functional associations of proteins identified in the up-regulated dataset, we used the Search Tool for Retrieval of Interacting Genes (STRING) (https:/ / string-db.org/, accessed on 27 May 2020) database that encompasses known and predicted protein-protein interactions (PPI) followed by identification and analysis of functional clusters in the PPI network.

Starting initially from the list of differentially expressed proteins with a significantly increased abundance in the BRAF mutant colon cancer cell line, we retrieved the enriched protein-protein interaction dataset from the DAVID online functional annotation tool, 
which was then uploaded into STRING to finally construct the PPI network consisting of 235 nodes and 641 edges, with a confidence score of 0.900 and an average local clustering coefficient of 0.546 (PPI enrichment $p$-value $<1.0 \times 10^{-16}$ ) (Figure 2).

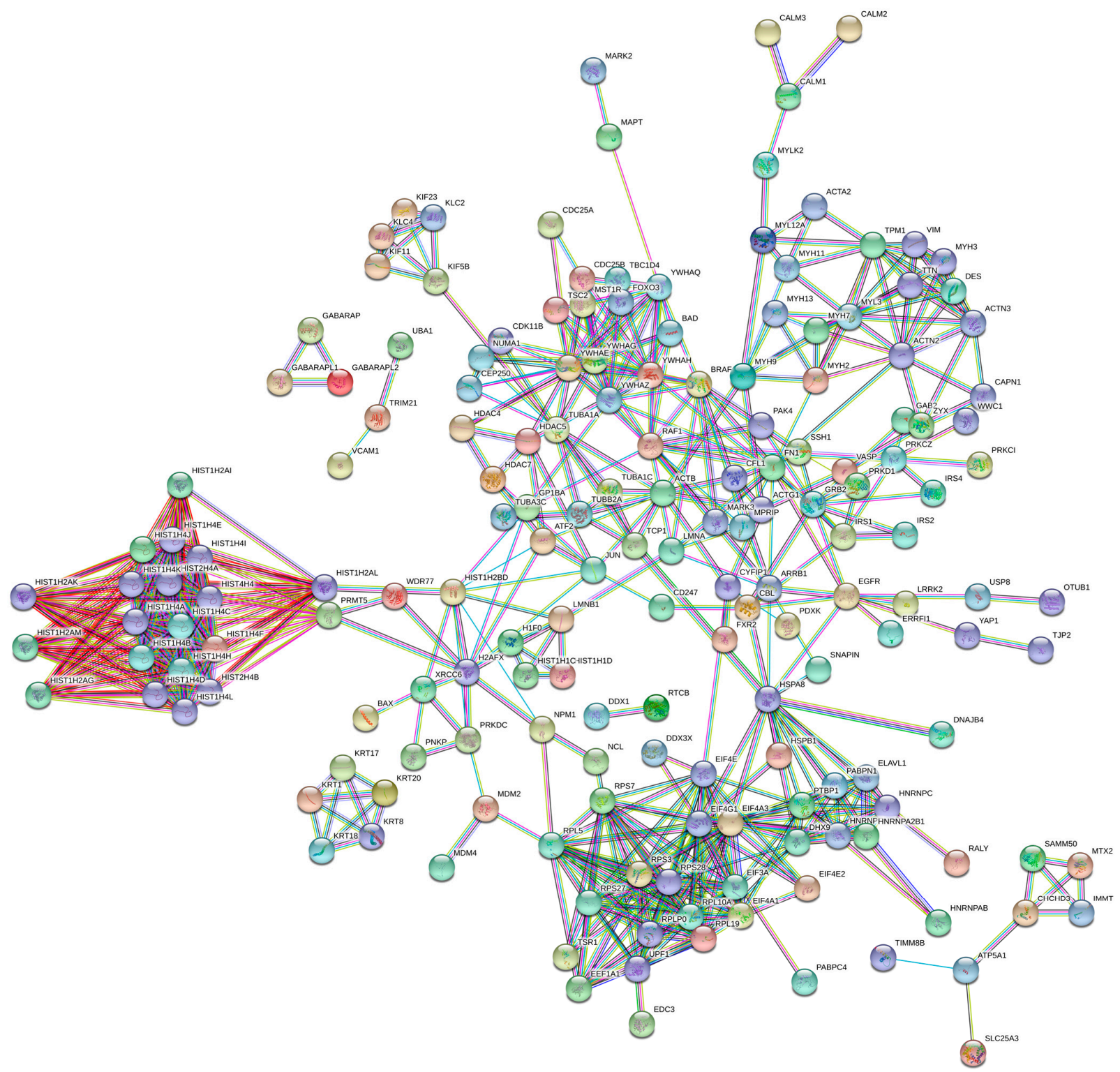

Figure 2. Protein-protein interaction (PPI) network of up-regulated proteins in BRAFV600E mutant HT-29 colon cancer cells and their interaction partners retrieved from the DAVID functional enrichment tool. The PPI network was constructed using the STRING database of known and predicted protein-protein interactions with the highest confidence of 0.900 .

We next visualized the network in Cytoscape, and using the MCODE plugin, we identified and visualized eight significant modules/clusters with an MCODE score of $\geq 4$ and a number of nodes of $>4$ (Supplementary Table S4). Using the Cytohubba plugin, we then ranked the top 10 hub genes in each significant module based on two topological analysis methods: maximal clique centrality (MCC) and degree (Supplementary Table S4). Functional analysis of the genes in important modules revealed that they were mainly associated with histone structure and modifications (demethylation, methylation and deacetylation), pointing to epigenetic mechanisms (module 1); ribosome structure, biogenesis and protein synthesis (module 2); RNA metabolism and signaling by interleukins (module 3); actin cytoskeleton, cell movement, cell-cell communication and cell cycle regulation via G2/M checkpoints (module 4); regulation of microtubule dynamics and chromosome and cen- 
trosome positioning during mitosis (module 5); organization and structure of the keratin cytoskeleton (module 6); mitochondrial biogenesis (module 7); chromosome maintenance, nucleosome assembly, centromere organization and activation of transcription (module 8).

Altogether, bioinformatics analyses provided a broader perspective on the obtained proteomics data by revealing several events that might be associated with the BRAFV600E mutation in colon cancer including cytoskeleton remodeling, transcriptional and epigenetic dysregulations, increased ribosome biogenesis and protein synthesis, positive regulation of the cell cycle, centrosome cycle and mitosis and metabolic alterations linked with methionine and serine biosynthesis.

\subsection{In Vitro and In Silico Validation of Proteomic Data Reveals Increased Abundance of Nucleophosmin in BRAFV600E-Mutated Colon Cancer}

Based on the observations from bioinformatics analyses, we opted for further in vitro validation of several protein targets arising from proteomic data that specifically regulate ribosome biogenesis, centrosome duplication and histone assembly (NPM1), mitotic spindle assembly and progress through mitosis (RanBP1), protein synthesis (eIF4E) and methionine (ENOPH1) and serine (PSPH) biosynthesis. Since many of these proteins including NPM1 [13], RanBP1 [14], eIF4E [15] and PSPH [16] were previously reported to be transcriptional targets of c-Myc, expression of c-Myc in colon cancer cell lines differing in their BRAF mutational status was also examined.

Baseline expression levels of selected protein targets were investigated by western blot in two BRAFV600E mutant colon cancer cell lines harboring WT KRAS (HT-29 and RKO), two WT BRAF cell lines carrying KRAS mutations (HCT 116 and SW480) and a double WT colon cancer cell line (Caco-2). Amongst all studied proteins, only the expression levels of NPM1 and phospho-c-Myc (Ser62) showed a trend towards an increase in both BRAF-mutated cell lines (Figure 3), albeit statistically non-significant when compared to other cell lines. Interestingly, a statistically significant difference was observed with up-regulated levels of PSPH in HT-29 cells in comparison with other cell lines carrying wild-type BRAF (Figure 3). However, this pattern of PSPH expression was not replicated in the RKO cell line, which could be, at least partially, explained by the difference in the mutational status of the $p 53$ gene between these two cell lines, which is critically involved in the regulation of amino acid metabolism in cancer cells [17].

Next, we analyzed the mRNA expression profiles of selected targets in BRAF mutant colon cancer in The Cancer Genome Atlas (TCGA) colon adenocarcinoma cohort using cBioPortal and found that only the NPM1 mRNA expression level was significantly increased $(p=0.0498)$ in BRAFV600E mutant colon cancer in comparison with WT BRAF (Figure 4). Although not significant, mRNA expression levels of ENOPH1, RANBP1 and EIF4E were higher in BRAFV600E mutant colon cancer than in the unaltered group. An opposite trend in the mRNA expression was observed for MYC and PSPH whose gene expression was higher in the unaltered group (Figure 4). The discrepancy between the results obtained for MYC and PSPH at the protein level revealed by western blot and their respective mRNA expression levels retrieved from the TCGA database could be, at least partially, ascribed to different biological sources (cells vs. tissues) and to a poor correlation between mRNA and protein levels [18].

Altogether, data from in vitro and in silico studies indicate an increased abundance of nucleophosmin in BRAF mutant colon cancer.

\subsection{Nucleophosmin and c-Myc Mediate Resistance to BRAFV600E Inhibition by PLX4032 in BRAFV600E Mutant Colon Cancer Cell Lines}

In order to investigate the role of nucleophosmin and its interaction partner c-Myc in the response and development of acquired resistance to BRAFV600E inhibition by vemurafenib (PLX4032), we measured the expression levels of NPM1, c-Myc and their phosphorylated forms p-NPM1 (Thr199) and p-c-Myc (Ser62) in sensitive colon cancer cell lines HT-29 and RKO and their vemurafenib-resistant counterparts HT-29r and RKOr, 
respectively, after exposure to cytotoxic concentrations ( $\mathrm{IC}_{50}$ ) of PLX4032 (Supplementary Table S5) for 24, 48 and $72 \mathrm{~h}$.

Although PLX4032 did not have obvious effects on the expression profiles of NPM1 in both parental cell lines and their resistant counterparts, more immense alterations in the expression level of p-NPM1 (Thr199) were observed upon treatment with PLX4032. Specifically, parental HT-29 cells responded to PLX4032 by dramatically reducing the level of p-NPM1 (Figure 5a,b). On the contrary, PLX4032 induced a statistically significant increase in the expression level of p-NPM1 in resistant HT-29r cells after $24 \mathrm{~h}$ when compared to sensitive cells. A similar pattern of p-NPM1 expression in response to PLX4032 was detected in RKO cells (Figure 5c,d). Thus, in parental cells treated with PLX4032, there was a trend toward a consistent decrease in the expression level of p-NPM1, as opposed to resistant cells that gradually up-regulated their levels of p-NPM1, peaking at $48 \mathrm{~h}$ after the treatment. Altogether, treatment with PLX4032 resulted in a surge in p-NPM1 expression in both resistant cell lines, although with a different magnitude and temporal dynamics. As previously reported, phosphorylation of NPM1 by CDK2-cyclin E on threonine 199 triggers its dissociation from unduplicated centrosomes in the G1 phase, which promotes initiation of centrosome duplication [19]. With this in mind, it is tempting to believe that nucleophosmin might regulate the resistance to PLX4032 via the mechanisms that propel centrosome duplication.

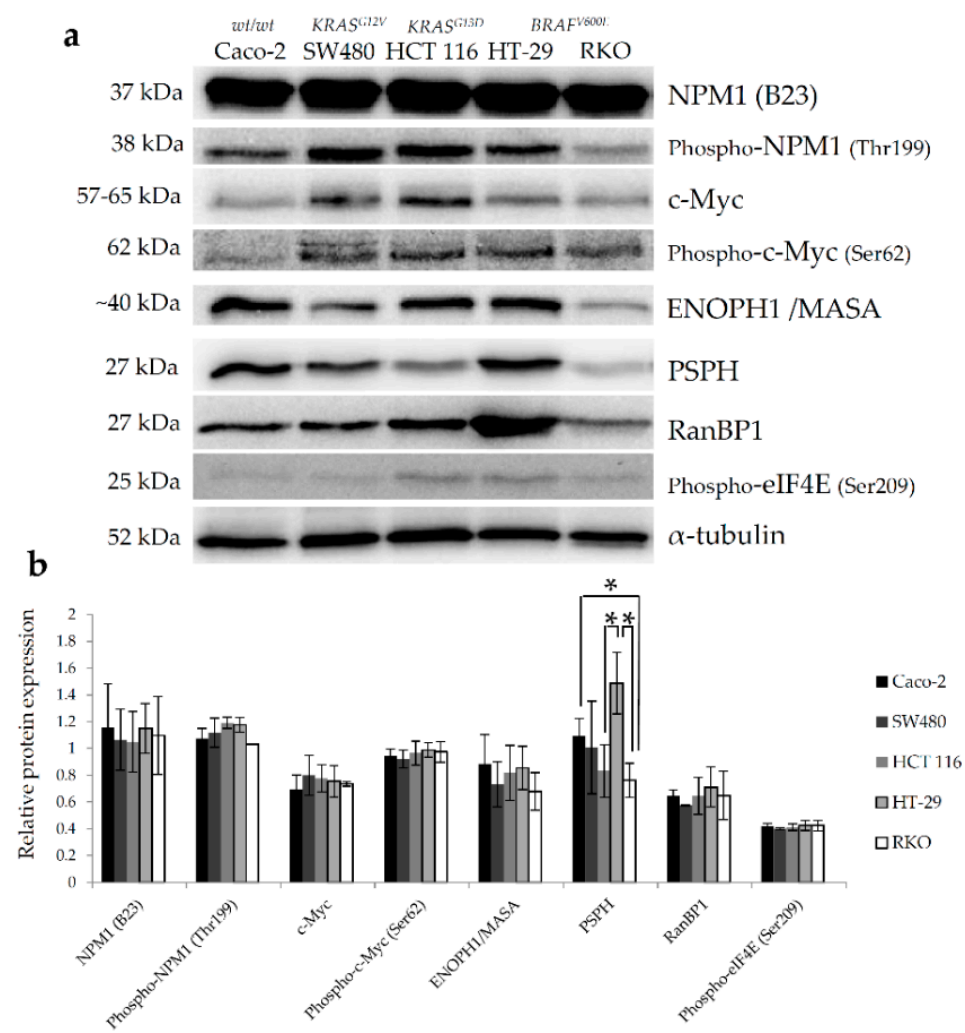

Figure 3. Western blot analysis of baseline levels of protein candidates chosen from proteomic dataset of up-regulated proteins in BRAFV600E mutant colon cancer cells following bioinformatics analyses. (a) Representative western blot images showing the baseline expression levels of selected proteins in two BRAFV600E mutant colon cancer cell lines harboring WT KRAS (HT-29 and RKO), two WT BRAF cell lines carrying KRAS mutations (HCT 116 and SW480) and a double WT colon cancer cell line (Caco-2). $\alpha$-Tubulin was used as loading control. (b) Relative protein expression of selected proteins measured by densitometry analysis of individual bands using Quantity One software. Data represent mean and standard deviation obtained from three independent biological experiments. $\alpha$-Tubulin was used as loading control. Statistical significance where $p<0.05$ is denoted with an asterisk. 

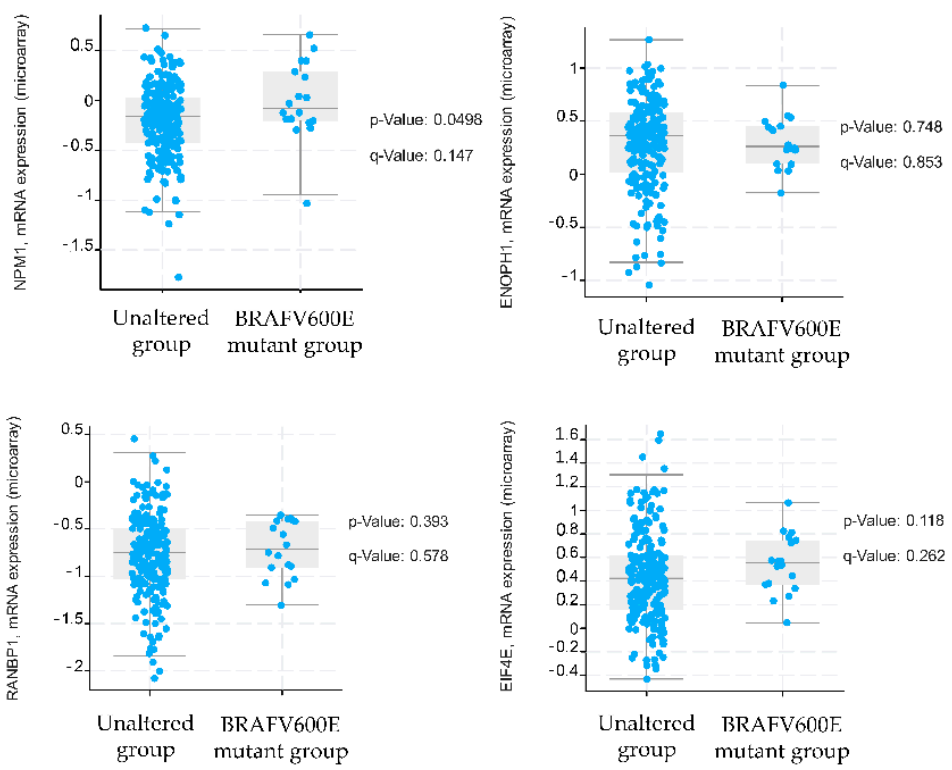

b

Upregulated in Unaltered group
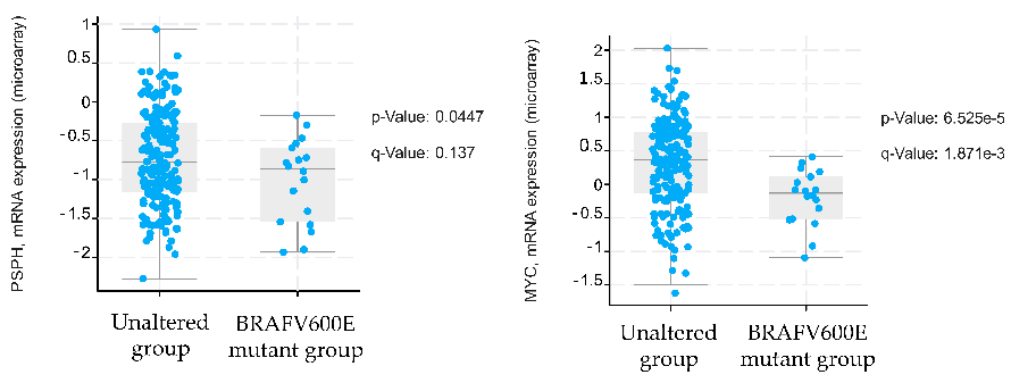

Figure 4. Validation of selected protein candidates in the Cancer Genome Atlas (TCGA) database. Shown here are mRNA expression levels corresponding to selected proteins using the colorectal adenocarcinoma dataset from the TCGA database in cBioPortal that included 20 cases with the BRAFV600E mutation and 200 cases without an indicated mutation (unaltered group). A $p$-value $<0.05$ was considered statistically significant.

RanBP1 constitutes a component of the Ran-CRM1 complex that regulates centrosome duplication by controlling NPM1 cytoplasmic translocation and its association with centrosomes [20]. RanBP1 could inhibit the function of CRM1, resulting in NPM1 dissociation from the centrosomes and initiation of centrosome duplication. Treatment of parental HT-29 cells with PLX4032 gave rise to a sustained decline in the RanBP1 expression levels (Figure 5a,b). Importantly, the expression of RanBP1 was markedly increased in resistant HT-29r cells in comparison with parental cells peaking at $24 \mathrm{~h}$ after the treatment, which paralleled the expression pattern of p-NPM1 in resistant HT-29r cells exposed to PLX4032. Although parental RKO cells did not exert pronounced alterations in the RanBP1 expression profile within the tested timeframe, resistant RKOr cells did show a consistent increase in the RanBP1 expression levels with a statistical significance after $72 \mathrm{~h}$ of treatment (Figure 5c,d). The increased regulation of RanBP1 expression in resistant cell lines in response to PLX4032 challenge further supports the relevance of the mechanisms regulating initiation of centrosome duplication in the development of drug resistance in BRAF-mutated colon cancer cells. 

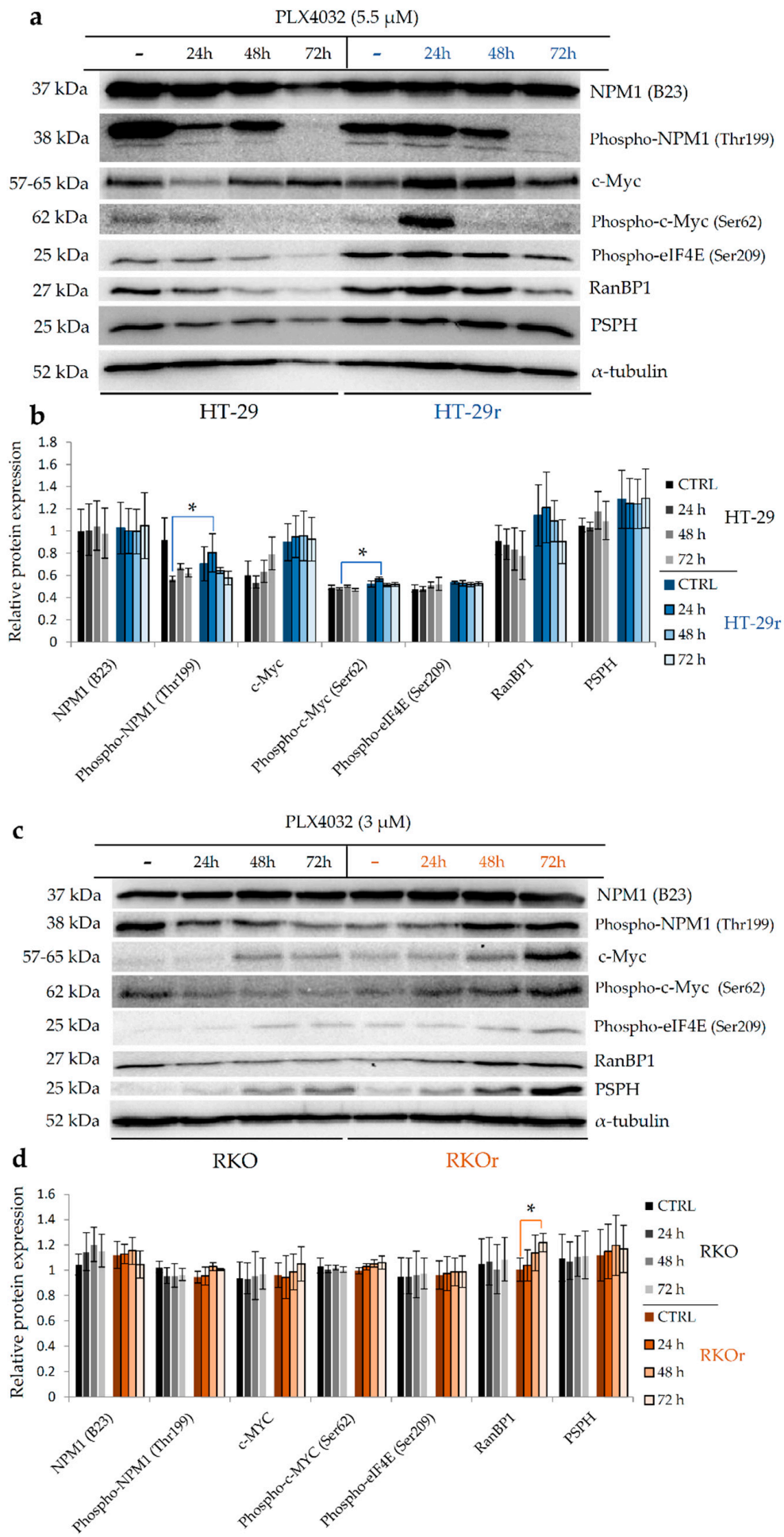

Figure 5. Western blot analysis of relative expression of selected proteins in BRAFV600E-mutated HT29 (a,b) and RKO (c,d) sensitive and vemurafenib (PLX4032)-resistant colon cancer cell lines following the exposure to cytotoxic concentrations of PLX4032 at different time points. Densitometry analysis of western blot bands was carried out by Quantity One software to calculate relative abundance of selected proteins in parental and resistant HT-29 (b) and RKO (d) cells. Data represent mean and standard deviation obtained from two independent biological experiments with two technical replicates. $\alpha$-Tubulin was used as loading control. Statistical significance where $p<0.05$ is denoted with an asterisk. 
The expression and activity of c-Myc, a common transcriptional regulator of NPM1 and RanBP1 and an interaction partner of NPM1, were also differentially regulated between sensitive and resistant cell lines after the PLX4032 challenge. The levels of c-Myc were generally higher in resistant HT-29r cells before and after the exposure to PLX4032 when compared with sensitive HT-29 cells (Figure 5a,b). Importantly, a statistically significant increase in the p-c-Myc level was observed in HT-29r cells after $24 \mathrm{~h}$ of treatment when compared to sensitive cells. Similarly, a trend towards a sustained increase in the levels of c-Myc and p-c-Myc peaking at $72 \mathrm{~h}$ after the exposure to PLX4032 was observed in resistant RKOr cells when compared to their sensitive counterpart (Figure 5c,d).

c-Myc plays a central role in the regulation of cancer cell metabolism including amino acid metabolism, where it functions as a positive regulator of the serine synthesis pathway. Thus, the expression of the enzyme catalyzing the last step in the biosynthesis of serine, namely, phosphoserine phosphatase (PSPH), is positively regulated by c-Myc at the gene and protein levels, and PSPH seems to be important for the oncogenic function of c-Myc in vitro and in vivo [16]. In line with this, the PSPH expression pattern measured in resistant cell lines exposed to PLX4032 paralleled the expression and activity of c-Myc (Figure 5). Thus, the expression levels of PSPH were generally higher in HT-29r before and after the PLX4032 challenge when compared to HT-29 cells, whereas RKOr cells exerted a trend towards increased levels of PSPH after the treatment with PLX4032 relative to sensitive RKO cells.

Previous studies have shown altered levels of eIF4E in response to changes in the c-Myc levels and provided evidence to support the transcriptional activation of eIF4E by c-Myc [15]. We found that the levels of p-eIF4E (Ser209) did not change markedly in response to PLX4032 over the treatment period of $72 \mathrm{~h}$ in resistant and parental cell lines (Figure 5), and that its expression levels were not remarkably different between responsive and non-responsive cell lines. This finding led us to conclude that eIF4E is not critically involved in the regulation of the drug response and resistance to BRAF inhibition in BRAFV600E mutant colon cancer cells.

Collectively, our data put forward the possibility that molecular events associated with centrosome duplication, mitosis, transcription machinery and serine metabolism could play an important role in determining the responsiveness of BRAF mutant colon cancer cells to BRAF inhibition by PLX4032. Given the central regulatory roles of NPM1 and c-Myc in these processes, their targeting could provide novel opportunities to counteract drug resistance in BRAF mutant colon cancer.

\subsection{Tumour Tissues from BRAF-Mutated Colon Adenocarcinoma Patients Have Significantly Increased Abundance of Cytoplasmic p-NPM1 (Thr199)}

Since our data indicate the role of p-NPM1 (Thr199) in regulating the resistance of BRAF-mutated colon cancer cells to BRAF inhibition, we hypothesized that tumor tissues from BRAF-mutated colon cancer patients, who present with an aggressive clinical phenotype and have a generally poor response to systemic chemotherapy, could have an increased abundance of p-NPM1. In order to verify this presumption, we examined the levels of $p$-NPM1 (Thr199) in tumor tissues from colon adenocarcinoma (CA) patients with different BRAF mutational statuses using immunohistochemistry. We observed that all CAs had positive nuclear staining of nucleophosmin (phospho threonine 199), but with different staining intensities, and none of the tissue samples were negative (Figure 6, Table 4, Supplementary Table S6). When we analyzed the cytoplasm of tumor cells, we observed that there was a greater difference in staining intensity, from negative to strong.

In the group of BRAF-mutated CAs, the nuclear staining intensity of nucleophosmin (phospho T199) was predominantly strong. In addition, BRAF-mutated CAs also had a strong cytoplasmic staining intensity. In colonic adenocarcinomas with the KRAS mutation, nuclei were moderately stained with a weak to negatively stained cytoplasm. Colonic adenocarcinomas that were BRAF and KRAS wild types had moderate to strong nuclear staining, and weak to negative cytoplasmic staining (Figure 6, Table 4, Supplementary Table S6). 


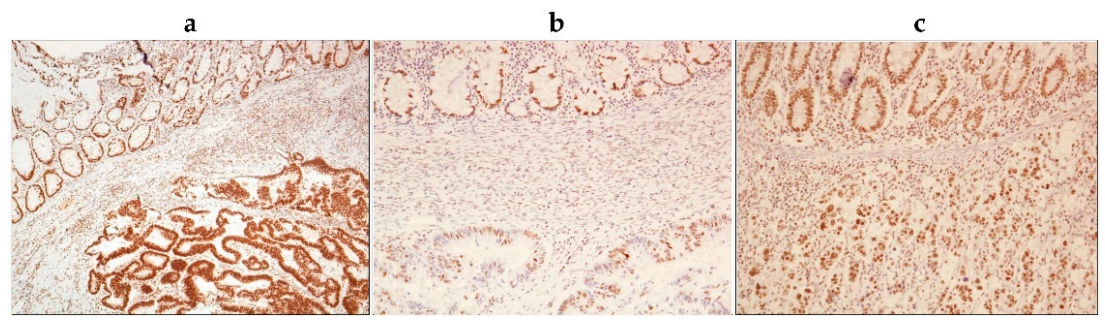

Figure 6. Representative microphotographs of immunohistochemical staining of phosphonucleophosmin (Thr199) in colonic adenocarcinomas differing in BRAF mutational status. (a) Upper part of the picture showing normal colonic crypts, with moderate nuclear staining. Below is colonic adenocarcinoma with BRAF mutation showing strong nuclear and cytoplasmic staining; (b) upper part of the picture showing normal colonic crypts, with moderate nuclear staining. Below is colonic adenocarcinoma with KRAS mutation showing weak nuclear and negative cytoplasmic staining; (c) upper part of the picture showing normal colonic crypts, with moderate nuclear staining. Below is colonic adenocarcinoma BRAF and KRAS wild types showing moderate nuclear and negative cytoplasmic staining. Magnification $100 \times(6 \mathbf{a})$ and $200 \times(6 \mathbf{b}$ and $6 \mathbf{c})$.

Table 4. The immunohistochemistry staining intensity of nucleophosmin in colonic adenocarcinomas differing in BRAF mutational status.

\begin{tabular}{cccc}
\hline & BRAF mut & BRAF wt & \\
\hline & $\mathbf{N}=\mathbf{7}(\mathbf{3 3} \%)$ & $\mathbf{N}=\mathbf{1 4} \mathbf{( 6 7 \% )}$ & \\
\hline Staining intensity & mean & mean & $p$-value \\
\hline Nuclear & 2 & 1.43 & 0.009 \\
\hline Cytoplasmic & 1.86 & 0.86 & 0.005 \\
\hline
\end{tabular}

When we compared nuclear staining of nucleophosmin ( $p$-T199) in BRAF-mutated vs. BRAF wild-type CAs (with and without the KRAS mutation), there was a statistically significant difference between these two groups (Student's $t$-test, $p=0.009$ ), even in such a small sample size (Table 4). Importantly, a greater difference was seen in the cytoplasmic staining intensity of nucleophosmin (p-T199). BRAF-mutated CAs mostly had a strong staining intensity of their cytoplasm compared to BRAF wild-type CAs, which stained mostly weak to negative. This observation was also statistically significant (Student's $t$-test, $p=0.005$ ). Altogether, these results point to a significantly increased abundance of cytoplasmic $p$-NPM1 (Thr199) in tumor tissues from BRAF-mutated in comparison with wild-type BRAF CA patients.

\subsection{Pharmacological Inhibition of Oncogenic Nucleophosmin/MYC Axis Restores Sensitivity of BRAF Mutant Colon Cancer Cells to PLX4032}

Prompted by the findings that resistant BRAF-mutated colon cancer cells exposed to cytotoxic doses of PLX4032 express an increased activity of nucleophosmin associated with the promotion of centrosome duplication concomitant with an increased stability and activity of its binding partner, c-Myc, we sought to further investigate whether pharmacological targeting of NPM1 and c-Myc could increase the efficacy of PLX4032 in resistant cell lines. NPM1 was specifically inhibited by NSC348884, a small molecule inhibitor that targets nucleophosmin oligomer formation, leading to consequent impairment of its function [21]. Resistant cell lines RKOr and HT-29r were pre-treated with either $\mathrm{IC}_{50}$ or $2 \times \mathrm{IC}_{50}$ concentrations of NSC 348884 for 2 and $4 \mathrm{~h}$ followed by culturing the cells in the presence of five different concentrations of PLX4032 $\left(10^{-8}\right.$ to $\left.10^{-4} \mu \mathrm{M}\right)$ for a total period of $72 \mathrm{~h}$. In both resistant cell lines, pre-treatment with $\mathrm{IC}_{50}$ concentrations of NSC348884 for $2 \mathrm{~h}$ induced an obvious reduction in cell viability in comparison with single-agent PLX4032, and this effect was markedly potentiated in both resistant cell lines after pre-treatment with $2 \times \mathrm{IC}_{50}$ concentrations of NSC348884, which strongly suppressed cell proliferation, as 
evidenced by more than a two-fold decrease in $\mathrm{IC}_{50}$ values in comparison with single-agent PLX4032 (Table 5). Importantly, the longer pre-treatment period of $4 \mathrm{~h}$ in the presence of $2 \times \mathrm{IC}_{50}$ concentrations of NSC348884 produced a dramatic reduction in cell viability in both resistant cell lines in comparison with a single treatment with PLX4032.

Table 5. Anti-proliferative effect of PLX4032 in BRAF mutant colon cancer cells with acquired resistance to PLX4032 after 2and 4-h pre-treatment with cytotoxic concentrations of nucleophosmin inhibitor NSC348884 measured by the MTT assay. Shown here are the results from two independent experiments expressed as mean \pm standard deviation.

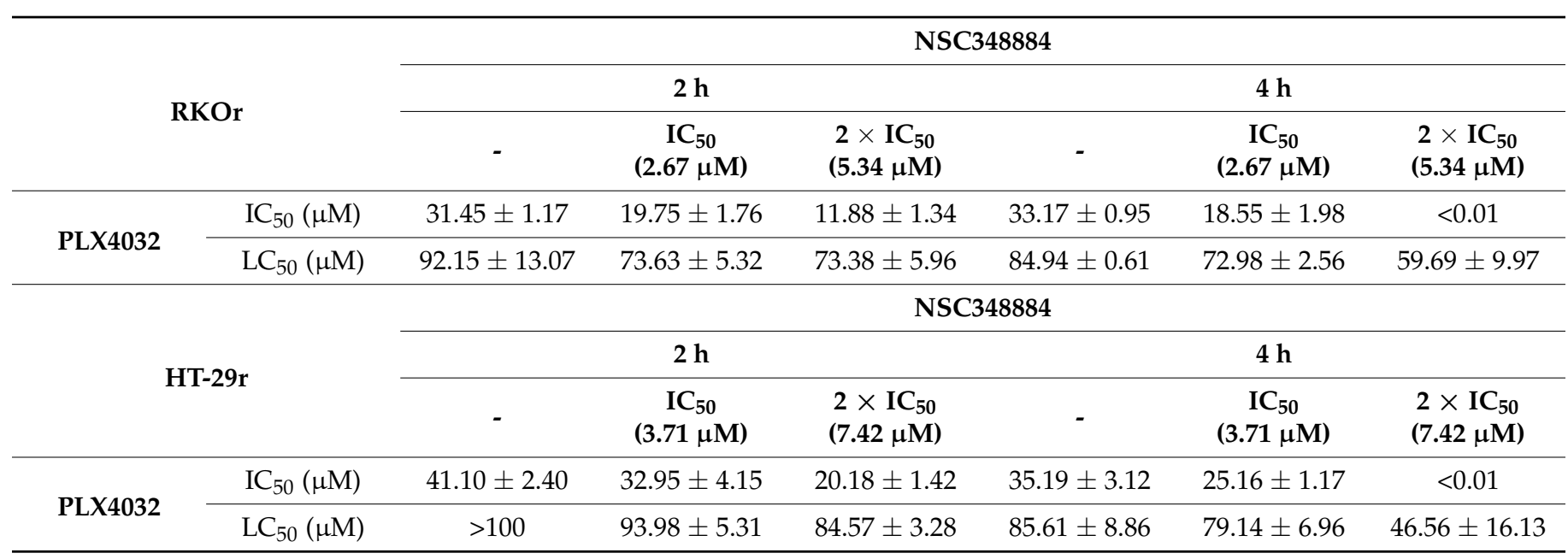

We next examined the effects of pre-treatment with IZCZ-3 on the response of resistant cell lines to PLX4032. IZCZ-3 stabilizes the G-quadruplex structure in the c-Myc promoter, resulting in the suppression of c-Myc transcription [22]. Generally, pre-treatment with IZCZ-3 produced a more potent anti-proliferative effect in combination with PLX4032 in resistant RKO cells than in resistant HT-29 cells (Table 6), which could be, at least partially, ascribed to the fact that, unlike HT-29 cells, RKO cells harbor the wild-type $p 53$ gene which represses c-Myc transcription and suppresses c-Myc-induced cell proliferation [23]. Thus, the inhibitory effect of IZCZ-3 on c-Myc in RKO resistant cell line could be additionally augmented by a negative feedback regulation of c-Myc expression by WT $p 53$, resulting in a marked cytostatic effect, particularly after pre-treatment with $2 \times \mathrm{IC}_{50}$ concentration of IZCZ-3 (Table 6).

Table 6. Anti-proliferative effect of PLX4032 in BRAF mutant colon cancer cells with acquired resistance to PLX4032 after 6and 8-h pre-treatment with cytotoxic concentrations of c-Myc transcription inhibitor IZCZ-3 measured by the MTT assay. Shown here are the results from two independent experiments expressed as mean \pm standard deviation.

\begin{tabular}{|c|c|c|c|c|c|c|c|}
\hline \multirow{3}{*}{\multicolumn{2}{|c|}{ RKOr }} & \multicolumn{6}{|c|}{ IZCZ-3 } \\
\hline & & \multicolumn{3}{|c|}{$6 \mathrm{~h}$} & \multicolumn{3}{|c|}{$8 \mathrm{~h}$} \\
\hline & & - & $\begin{array}{c}\mathrm{IC}_{50} \\
(0.58 \mu \mathrm{M})\end{array}$ & $\begin{array}{c}2 \times \mathrm{IC}_{50} \\
(1.16 \mu \mathrm{M})\end{array}$ & - & $\begin{array}{c}\mathrm{IC}_{50} \\
(0.58 \mu \mathrm{M})\end{array}$ & $\begin{array}{c}2 \times \mathrm{IC}_{50} \\
(1.16 \mu \mathrm{M})\end{array}$ \\
\hline \multirow{2}{*}{ PLX4032 } & $\mathrm{IC}_{50}(\mu \mathrm{M})$ & $30.22 \pm 0.34$ & $8.73 \pm 0.01$ & $4.57 \pm 0.63$ & $29.71 \pm 1.03$ & $7.74 \pm 0.66$ & $2.36 \pm 1.30$ \\
\hline & $\mathrm{LC}_{50}(\mu \mathrm{M})$ & $82.89 \pm 6.48$ & $71.09 \pm 2.92$ & $66.42 \pm 1.49$ & $85.88 \pm 1.94$ & $77.06 \pm 1.47$ & $61.80 \pm 12.90$ \\
\hline \multirow{3}{*}{\multicolumn{2}{|c|}{ HT-29r }} & \multicolumn{6}{|c|}{ IZCZ-3 } \\
\hline & & & $6 \mathrm{~h}$ & & & $8 \mathrm{~h}$ & \\
\hline & & - & $\begin{array}{c}\mathrm{IC}_{50} \\
(0.35 \mu \mathrm{M})\end{array}$ & $\begin{array}{c}2 \times \mathrm{IC}_{50} \\
(0.70 \mu \mathrm{M})\end{array}$ & - & $\begin{array}{c}\mathrm{IC}_{50} \\
(0.35 \mu \mathrm{M})\end{array}$ & $\begin{array}{l}2 \times \mathrm{IC}_{50} \\
(0.70 \mu \mathrm{M})\end{array}$ \\
\hline \multirow{2}{*}{ PLX4032 } & $\mathrm{IC}_{50}(\mu \mathrm{M})$ & $37.81 \pm 4.17$ & $31.76 \pm 3.29$ & $26.43 \pm 4.51$ & $39.99 \pm 1.49$ & $32.03 \pm 3.13$ & $17.90 \pm 3.23$ \\
\hline & $\mathrm{LC}_{50}(\mu \mathrm{M})$ & $90.13 \pm 1.02$ & $75.49 \pm 1.76$ & $77.49 \pm 0.52$ & $94.27 \pm 9.43$ & $80.13 \pm 1.28$ & $73.30 \pm 1.00$ \\
\hline
\end{tabular}


As for HT-29 resistant cells that carry the mutant $p 53$ gene, more pronounced antiproliferative effects in combination with PLX4032 were observed only with $2 \times \mathrm{IC}_{50}$ concentration of IZCZ-3 after an 8-h pre-treatment (Table 6). The modest chemosensitization effect of IZCZ-3 in HT-29r cells could be potentially explained by the previous findings revealing that mutant $p 53$ induces the expression of the endogenous $c-m y c$ gene via the activation of the $c-m y c$ promoter [24]. With this in mind, we cannot rule out the possibility that mutant $p 53$-dependent induction of c-Myc in HT-29 resistant cells overrides its inhibition by IZCZ-3 to enable cellular proliferation and survival. Targeting c-Myc with IZCZ-3 may not thus be sufficient to maximize the cytotoxic effects of vemurafenib in resistant cells due to the possible impact of the mutational status of the $p 53$ gene, which does not seem to be the case with targeting NPM1 by NSC348884. Importantly, the magnitude of the cytostatic effects induced by NSC348884, especially after a longer treatment period with $2 \times \mathrm{IC}_{50}$ concentration, was not reached with IZCZ-3. These findings hint that nucleophosmin might be a putative target to overcome resistance to vemurafenib in BRAF-mutated colon cancer cells regardless of the presence of other oncogenic mutations.

In order to further investigate whether the observed anti-proliferative effects induced by pharmacological inhibition of NPM1 could be attributed to suppression of its binding partner, c-Myc, and abrogation of c-Myc-driven cellular events, we carried out western blot analysis of resistant cell lines treated with $2 \times \mathrm{IC}_{50}$ of NSC348884 for 4,6 and $8 \mathrm{~h}$. We found that inhibition of NPM1 oligomerization by NSC348884 significantly suppressed the expression of c-Myc and p-c-Myc in HT-29r cells (Figure 7). In addition, a trend towards a reduction in c-Myc and p-c-Myc levels in a time-dependent manner was also observed in RKOr cells after the treatment with NSC348884. The observed decline in c-Myc and p-c-Myc levels was accompanied by an obvious decrease in RanBP1 levels in both resistant cell lines as early as $6 \mathrm{~h}$ after the treatment with NSC348884. Similarly, PSPH levels descended in both resistant cell lines exposed to NSC348884, although with different temporal dynamics and intensities (Figure 7).
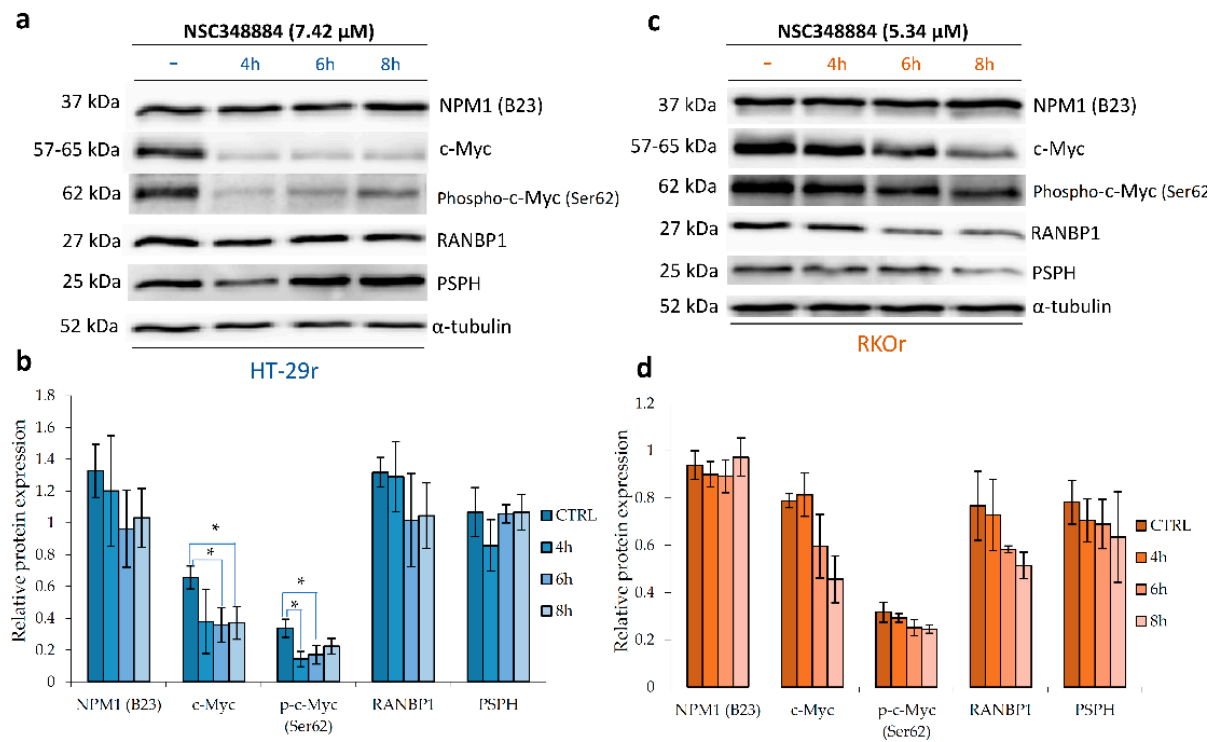

Figure 7. Western blot analysis of relative protein expression of nucleophosmin, c-Myc and its transcriptional targets RanBP1 and phosphoserine phosphatase (PSPH) in vemurafenib-resistant HT-29r $(\mathbf{a}, \mathbf{b})$ and RKOr $(\mathbf{c}, \mathbf{d})$ colon cancer cells with BRAFV600E mutation after the treatment with cytotoxic concentrations of nucleophosmin inhibitor NSC348884 for indicated time periods. Densitometry analysis of western blot bands was carried out by Quantity One software to calculate relative protein abundance $(\mathbf{b}, \mathbf{d})$. Data represent mean and standard deviation obtained from two independent biological experiments with two technical replicates. $\alpha$-Tubulin was used as loading control. Statistical significance where $p<0.05$ is denoted with an asterisk. 
To sum up, findings from this study indicate that inhibition of NPM1 oligomerization increases the responsiveness of resistant cells to vemurafenib by mechanisms that might include down-regulation of c-Myc transcription and activity, leading to attenuation of downstream signaling regulated by RanBP1 and PSPH.

\section{Discussion}

In this paper, we described up-regulated proteomic features that could be associated with the BRAFV600E mutation in colon cancer cells. Previous studies mainly focused on identifying characteristic gene expression patterns of BRAFV600E-mutated colon cancer by examining differences between oncogenic BRAF vs. either the KRAS mutation $[4,7,25]$ or double wild-type BRAF/KRAS [5,6]. However, our study goes beyond previous reports by contrasting the BRAF mutant with both BRAF wild-type/KRAS mutant and double wild-type BRAF/KRAS phenotypes to circumvent the possibility of identifying overlapping features between oncogenic BRAF- and KRAS-driven biology. The results from our bioinformatics analyses of the up-regulated proteomic dataset partially replicate previous findings from gene expression analyses in BRAFV600E mutant colon cancer by revealing some common molecular events. Specifically, actin cytoskeleton organization was identified as an important process associated with up-regulated proteins and genes in our and similar studies, respectively, which suggests that activating the BRAFV600E mutation affects the cytoskeletal structure and dynamics in colon cancer $[7,25]$. A similar conclusion was reached in melanoma cells by showing that BRAFV600E mutant expression contributes to oncogene-mediated reorganization of the actin cytoskeleton and focal adhesions [26]. Importantly, remodeling of the actin cytoskeleton was demonstrated in BRAFV600E mutant melanoma cells with acquired resistance to BRAF inhibitor vemurafenib, and depletion of TESK1, a kinase that regulates actin cytoskeleton dynamics and reversed resistance to vemurafenib [27]. With this in mind, inhibition of actin remodeling could also prove to be a promising strategy to overcome resistance to vemurafenib in BRAF mutant colon cancer.

Another interesting result emerging from our study relates to increased baseline levels of phosphoserine phosphatase (PSPH) in HT-29 cells, an enzyme regulating serine biosynthesis. This finding is in good agreement with a previous study showing the upregulation of the key proteins central to the serine biosynthesis pathway, including PSPH, in BRAFV600E mutant relative to wild-type BRAF colon cancer cells [28]. In addition, the BRAFV600E mutation status was shown to be associated with the serine biosynthesis pathway in other cancer types including papillary thyroid carcinoma, where higher expression of PSPH and other serine metabolism-related proteins was found in BRAFV600E-mutated tumors [29]. Importantly, we demonstrated that PSPH expression levels rose following the exposure to vemurafenib in resistant cell lines derived from HT-29 and RKO in a timedependent manner, and this effect was not observed in parental cells. This finding further supports the role of serine biosynthesis in the development of resistance to vemurafenib in BRAF-mutated colon cancer cells. Similar to our findings, the role of the serine biosynthesis pathway in the mechanisms underlying the resistance to BRAFV600E inhibitors has been previously reported in melanoma, pancreatic and non-small cell lung cancer cells [30].

Besides some common and previously described features of BRAFV600E mutant colon cancer, our study reveals, for the first time, increased regulation of nucleophosmin (NPM1) expression in BRAFV600E-mutated colon cancer. NPM1 is involved in diverse cellular processes including ribosome biogenesis, centrosome duplication, protein chaperoning, histone assembly, cell proliferation and regulation of tumor suppressors p53/TP53 and ARF. High expression of NPM1 was previously shown to correlate with lymph node metastasis in colon cancer patients and to promote in vitro colon cancer cell proliferation, migration and invasion [31]. However, its involvement in the BRAFV600E-regulated cellular landscape in cancer has not been previously reported. We observed a trend towards an increased basal expression of the NPM1 protein in BRAF-mutated colon cancer cell lines in comparison with the cells carrying either WT BRAF/mutant KRAS or double WT $\mathrm{BRAF} / \mathrm{KRAS}$. Furthermore, analysis of the mRNA expression profile data from colon ade- 
nocarcinoma patients in the TCGA database revealed significant up-regulation of the NPM1 gene in BRAFV600E-mutated colon cancer. Importantly, we detected significantly stronger nuclear and, in particular, cytoplasmic staining of phospho-NPM1 (Thr199) in tumor tissue specimens from BRAFV600E-mutated in comparison with KRAS mutant/BRAF wild-type and double wild-type KRAS/BRAF colonic adenocarcinomas using immunohistochemistry. Phosphorylation of NPM1 on Thr199 by cyclin-dependent kinase 2 (CDK2)/cyclin E is critical for the physical separation of the paired centrioles, which triggers the initiation of centrosome duplication [19]. The role of NPM1 in regulating mitosis was corroborated in different studies showing that cancer cells undergoing mitosis have a high level of NPM1 phosphorylated on Thr199 predominantly localized to the cytoplasm and the centrosome of dividing cells [32,33]. Increased expression of NPM1 phosphorylated on Thr199 in tumor tissues from BRAF mutant colon cancer patients could be thus related to anomalies in the centrosome cycle leading to centrosome amplification, which is a common event in colon cancer linked with mutations in several cancer-associated genes including BRAF [34]. Observations from our study concur with data from previous reports that pointed to aberrant centrosomal activity in BRAFV600E-mutated colon cancer by revealing an increased expression of the genes encoding for several different centrosomal proteins in BRAF mutant colon cancer cells and tumor tissues [25].

The finding of increased expression and activity of NPM1 in BRAF-mutated colon cancer prompted us to examine its potential role in modulating the response and resistance to BRAFV600E inhibitor vemurafenib. While BRAFV600E-mutated parental cell lines reduced their levels of p-NPM1 (Thr199) following vemurafenib challenge, their resistant counterparts responded to vemurafenib exposure by ascending the levels of p-NPM1 (Thr199), which points to the promotion of the centrosome duplication cycle and mitosis as potential mechanisms underlying vemurafenib resistance. The same pattern of RanBP1 expression recorded in resistant cell lines after the treatment with vemurafenib lends further support to the idea that the development of resistance to vemurafenib in BRAF-mutated colon cancer cells is associated with centrosome amplification and mitotic progression. RanBP1, a RAN partner with the highest levels in G2 and mitosis, regulates mitotic spindle assembly by controlling the spatial distribution and the extent of mitotic Ran-GTP production and provides the spatial control of specific factors regulating mitotic microtubule function $[35,36]$. Similar to our findings, a previous study also identified mitosis as a potential vulnerability of BRAFV600E-mutated colon cancer cell lines by revealing RANBP2 as the gene indispensable for survival of BRAFV600E colon cancer cell lines with no effects on the viability of wild-type KRAS/BRAF colon cancer cells [6]. Depletion of RANBP2 in BRAFV600E mutant colon cancer cells impaired spindle formation and prolonged mitosis, ultimately inducing cell death, which led the authors to hypothesize that BRAF mutant colon cancer cells could be sensitive to microtubule-disrupting agents such as vinorelbine, and this presumption was indeed confirmed in vitro and in vivo [6].

Previous studies adduced a wealth of evidence to support the correlation between the expression of NPM1 and c-Myc [13]. NPM1 binds the $c$-myc gene promoter, resulting in transcriptional regulation of the $c-m y c$ gene [37]. In addition, the endogenous and exogenous NPM1 protein has the ability to directly interact with the c-Myc protein to regulate the expression of c-Myc target genes at the promoter [38]. NPM1 was shown to induce c-Myc transcriptional activity resulting in c-Myc-induced hyperproliferation and transformation [38]. The clue that NPM1 regulates c-Myc localization and function arose from a study showing that NPM1 facilitates the localization of the c-Myc protein to nucleoli and enhances its ability to induce rRNA synthesis involved in ribosome biogenesis [39]. Here, we have shown that an increased basal expression of NPM1 in BRAF mutant colon cancer cell lines coincides with an increased expression level of phospho-c-Myc (Ser62). Importantly, we detected an upsurge in the expression levels and activity of c-Myc in both resistant cell lines after the PLX4032 challenge, which implies that c-Myc plays an important role in modulating vemurafenib resistance in BRAF mutant colon cancer cells. Similarly, a study in BRAF mutant melanoma indicated that c-Myc is reactivated at the 
gene and protein levels in tumor tissues and cell lines with acquired resistance to BRAF inhibitors [40]. The same authors reported that resistant cells have higher MYC levels in comparison with their parental counterparts. Expectedly, MYC knockdown increased the sensitivity of resistant cells to BRAF inhibition. Our results are partially in accordance with these findings by revealing that inhibition of c-Myc transcription by IZCZ-3 selectively induced a marked increase in the response to vemurafenib in BRAFV600E mutant colon cancer cells carrying wild-type p53, which suggests that the chemosensitizing effect of c-Myc inhibition might be governed by the functional status of the $p 53$ gene. Inhibition of the nucleophosmin function by NSC348884 in vemurafenib-resistant colon cancer cell lines with a BRAF mutation potentiated the cytotoxic effects of vemurafenib in a concentrationand time-dependent manner, regardless of the $p 53$ status, to an extent that was not observed with c-Myc inhibition. These results posit that NPM1 might be a putative target to restore sensitivity to BRAF inhibitors in colon cancer. Furthermore, inhibition of NPM1 gave rise to attenuation of c-Myc expression and activity in resistant cells, leading to suppression of its transcriptional targets RanBP1 and PSPH that regulate the centrosomal cycle and serine biosynthesis, respectively, which confirms previous literature data on the NPM1-regulated expression and activity of c-Myc, and puts forward the idea that inhibition of multiple targets resulting from blockade of NPM1 activity could be an efficient approach to increase the efficacy of vemurafenib in resistant BRAF mutant colon cancer cells, at least under in vitro conditions.

In conclusion, we found that NPM1 expression and activity potentially associated with the regulation of centrosome duplication and mitotic progression are specifically increased in BRAFV600E mutant colon cancer cells and tumor tissues from BRAF-mutated colon adenocarcinoma patients. Cellular processes linked with the initiation of centrosome duplication, mitosis and serine metabolism could be possibly involved in determining the responsiveness of BRAF mutant colon cancer cells to BRAF inhibition by vemurafenib, where nucleophosmin and its interaction partner and downstream target c-Myc play central regulatory roles. Furthermore, our data argue that pharmacological inhibition of the NPM1 function could restore the sensitivity of vemurafenib-resistant colon cancer cells with the BRAFV600E mutation by mechanisms that include down-regulation of c-Myc expression and activity and consequent suppression of its transcriptional targets RanBP1 and phosphoserine phosphatase regulating centrosome duplication and serine biosynthesis, respectively. Findings from this study point to the therapeutic potential of targeting the NPM1/c-Myc axis in BRAF-mutated colon cancer and provide a framework to devise novel strategies for counteracting the resistance to BRAF inhibition in colon cancer.

\section{Materials and Methods}

\subsection{Cell Culturing and Development of Vemurafenib-Resistant Colon Cancer Cell Lines}

Human colon carcinoma cell lines Caco-2 (BRAFwt $/ \mathrm{KRAS}^{\mathrm{wt}}$ ), SW480 (BRAF ${ }^{\mathrm{wt}} /$ $\left.\mathrm{KRAS}^{\mathrm{G} 12 \mathrm{~V}}\right)$, HCT 116 (BRAF $^{\mathrm{wt}} / \mathrm{KRAS}^{\mathrm{G} 13 \mathrm{D}}$ ) and HT-29 and RKO (BRAFV600E $/ \mathrm{KRAS}^{\mathrm{wt}}$ ) were purchased from the ATCC and maintained in Dulbecco's Modified Eagle's Medium (DMEM) or Minimum Essential Medium (MEM) supplemented with 10\% fetal bovine serum (FBS), $2 \mathrm{mM}$ L-glutamine, penicillin $(100 \mathrm{U} / \mathrm{mL})$ and streptomycin $(100 \mu \mathrm{g} / \mathrm{mL})$ (Capricorn Scientific, Ebsdorfergrund, Germany) in a humified atmosphere with 5\% $\mathrm{CO}_{2}$ at $37^{\circ} \mathrm{C}$.

In order to eliminate molecular features of resistance that might be cell line-specific, we developed two vemurafenib (PLX4032)-resistant colon cancer cell lines derived from HT-29 and RKO cell lines by exposing the cells to successively increasing concentrations of PLX4032 (MedChemExpress, Monmouth Junction, NJ, USA) in a period of about 6 months until a clinically relevant dose $(11.52 \mu \mathrm{M})$ [41] was reached. Established resistance phenotypes were confirmed by the MTT assay showing an increase in the $\mathrm{IC}_{50}$ values by 8and 10-fold in the resistant HT-29 and RKO cells, respectively, in comparison with their sensitive counterparts (Supplementary Table S5). 


\subsection{Cell Viability Assay}

Cell viability was assessed using the MTT assay. Briefly, cells were seeded onto 96well microtiter plates at a seeding density of 3000 cells/well. The following day, cells were treated with test agents in five 10-fold serial dilutions $\left(10^{-4}-10^{-8} \mu \mathrm{M}\right)$ and further incubated for $72 \mathrm{~h}$. MTT assay was performed according to the manufacturer's instructions (Sigma-Aldrich, St. Louis, MO, USA). After the completion of the treatment period, cells were incubated with MTT reagent for $3 \mathrm{~h}$ in the dark followed by the addition of dimethyl sulfoxide (DMSO, Sigma-Aldrich, St. Louis, MO, USA). Absorbance was measured at $570 \mathrm{~nm}$ using a Sunrise Absorbance microplate reader (Tecan Life Sciences, Männedorf, Switzerland). Inhibitory and lethal concentrations $\left(\mathrm{IC}_{50}\right.$ and $\mathrm{LC}_{50}$, respectively) were calculated using linear regression analysis.

Pre-treatment of cells with either NSC348884 (MedChemExpress, Monmouth Junction, NJ, USA) or IZCZ-3 (MedChemExpress, Monmouth Junction, NJ, USA) was carried out at previously determined $\mathrm{IC}_{50}$ and $2 \times \mathrm{IC}_{50}$ values of each agent for indicated time periods. Following the treatment, cells were washed twice with fresh medium and further treated with five 10-fold serial dilutions of PLX4032 for $72 \mathrm{~h}$, and cell viability was assessed using the MTT assay as described above.

\subsection{Two-Dimensional Gel Electrophoresis and Image Analysis}

Cells were lysed in 2-DE lysis buffer containing 7M urea, 2M thiourea, $4 \%$ CHAPS and $1 \%$ DTT (Sigma-Aldrich, St. Louis, MO, USA USA) supplemented with protease inhibitor cocktail (Roche, Switzerland). A total of $800 \mu \mathrm{g}$ of proteins was solubilized in 2-DE rehydration buffer (7M urea, 2M thiourea, $4 \%$ CHAPS, $1 \%$ DTT and $0.2 \%$ Bio-Lyte ampholyte (Bio-Rad, Hercules, CA, USA), loaded onto $17 \mathrm{~cm} \mathrm{pH} \mathrm{4-7} \mathrm{IPG} \mathrm{strips} \mathrm{and}$ subjected to isoelectric focusing on PROTEAN IEF cell (Bio-Rad). The IEF conditions were as follows: $50 \mathrm{~V}$ for $12 \mathrm{~h}, 200 \mathrm{~V}$ for $15 \mathrm{~min}, 500 \mathrm{~V}$ for $1 \mathrm{~h}, 500-10,000$ for $3 \mathrm{~h}$ and $10,000 \mathrm{~V}$ for $5 \mathrm{~h}$. In the second dimension, proteins were resolved by 12\% SDS-polyacrylamide gels by PROTEAN II XL cell (Bio-Rad, Hercules, CA, USA). Gels were stained with Coomassie Blue G-250 (Sigma-Aldrich, St. Louis, MO, USA) overnight, and after washing in miliQ water, gel images were taken by ChemiDoc XRS+ Imager (Bio-Rad, Hercules, CA, USA). The 2-DE gel image analysis was carried out using Progenesis SameSpots 4.0 software (TotalLab, Newcastle upon Tyne, United Kingdom). The experiment was performed in four individual biological replicates for each cell line. ANOVA followed by post hoc Tukey's test was carried out to identify statistically significant differences in protein abundance between the datasets obtained for the three cell lines differing in their BRAF mutational status.

\subsection{MALDI-TOF/TOF Mass Spectrometry Analysis}

Each sample was mixed with matrix solution containing $\alpha$-cyano-4-hydroxycinnamic acid $(0.3 \mathrm{~g} / \mathrm{L} \mathrm{CHCA}$ in a solution containing 2:1 ethanol/acetone, $v / v)$ at the ratio of 1:10. A total amount of $1 \mu \mathrm{L}$ of the mixture containing sample/matrix solution was spotted onto the MALDI plate (AnchorChip $800 \mu \mathrm{m}$, Bruker Daltonics, Bremen, Germany) and kept at room temperature to allow crystallization to occur. An UltrafleXtreme MALDITOF/TOF mass spectrometer (Bruker Daltonics, Billerica, MA, USA) was used to perform MS analyses in the reflector mode in the $\mathrm{m} / \mathrm{z}$ range of 700-3500 Da. The MS spectra were externally calibrated with the mixture of Peptide Calibration Standard and Protein Calibration Standard I (Bruker Daltonics, Billerica, MA, USA) at the ratio of 1:5. FlexControl 3.4 software (Bruker Daltonics, Billerica, MA, USA) was applied to acquire and process spectra. FlexAnalysis 3.4 (Bruker Daltonics, Billerica, MA, USA) was applied to perform protein database searches. Proteins were identified using the Mascot 2.4.1 search engine (Matrix Science, London, UK). The following search parameters were applied: enzyme: trypsin; fixed modifications: carbamidomethylation on cysteine; variable modifications: oxidation on methionine; protein mass: unrestricted; peptide mass tolerance: $\pm 50 \mathrm{ppm}$; maximum missed cleavage: 2 . 


\subsection{Bioinformatic Analyses}

GO enrichment analysis using the DAVID functional annotation tool (https: / / david. ncifcrf.gov/, accessed on 20 May 2020) was used to elucidate the biological functions of proteins, where enriched GO terms with $p<0.05$ were considered as statistically significant. The Reactome pathway database (https://reactome.org/, accessed 7 April 2021) was applied for pathway enrichment analysis.

Enrichment to identify the interactor proteins of the selected proteomic dataset prior to generation of the protein-protein interaction network was performed by DAVID using the following criteria: the threshold for enrichment was set to log fold change (FC) $>1.5$ and $p<0.05$.

The Search Tool for Retrieval of Interacting Genes (STRING) (http:/ /string-db.org/, accessed on 27 May 2020) online tool was applied to construct the PPI network, where the confidence score was set to 0.900 (highest confidence). The PPI network was visualized by Cytoscape (https:/ / cytoscape.org/, accessed on 27 May 2020), an open source software platform for visualizing complex networks. Each node corresponds to a protein, whereas the edges represent the interactions between proteins that contribute to the same biochemical function or pathway.

In order to analyze and select significant modules of the PPI network, the Molecular Complex Detection (MCODE) plugin of Cytoscape was employed with the following module identification criteria: node score cutoff $=0.2$; degree cutoff $=2$; maximum depth $=100$; and $\mathrm{k}$-core $=2$ [42]. To further identify the hub proteins in selected significant modules (clusters), we used Cytohubba, a Cytoscape plugin.

\subsection{Human Tissue Samples}

Tissue samples of 21 colonic adenocarcinomas (CAs) (excluding rectal) were obtained from the archive of the Department of Pathology and Cytology, Clinical Hospital Center Rijeka, from 2015 to 2020. The diagnostic criteria of colonic adenocarcinoma were based on the WHO classification. All 21 CAs were tested for BRAF and KRAS mutations. Of 21 CAs, a total of 7 had the BRAFV600E mutation.

\subsection{Immunohistochemistry Analysis}

Immunohistochemical staining was performed on formalin-fixed, paraffin-embedded $4 \mu \mathrm{m}$ tissue sections of colonic adenocarcinoma and stained with antibody against phoshonucleophosmin (Thr199) antibody (Abcam). Tissue sections of $4 \mu \mathrm{m}$-thick paraffin blocks were placed on silane-coated slides and dried overnight at $37^{\circ} \mathrm{C}$. This was followed by deparaffinization with xylene three times over $10 \mathrm{~min}$ and then rehydration with $100 \%$ absolute ethyl alcohol for $5 \mathrm{~min}, 96 \%$ alcohol for $5 \mathrm{~min}$ and then $70 \%$ alcohol for $5 \mathrm{~min}$. The rehydration procedure was followed by rinsing in distilled water for $10 \mathrm{~min}$. Heat-induced pre-treatment was used to detect antigenic epitopes. Tissue slides for nucleophosmin detection were immersed in target retrieval solution (3 in 1) in a PT link apparatus for $20 \mathrm{~min}$ at a temperature of $97^{\circ} \mathrm{C}$. After cooling for $20 \mathrm{~min}$ at room temperature and rinsing in distilled water, the slides were ready for immunohistochemical staining. The "EnVision" immunohistochemical method with the REAL ENVISION DETECTION system on the Dako Cytomation, Autostainer plus, Glostrup, Denmark automated dye was used to determine protein expression according to the manufacturer's instructions. The dilution of the primary antibody was 1:1000, and the incubation of the primary antibody was $30 \mathrm{~min}$. The negative control in each tissue specimen consisted of the substitution of primary $\mathrm{mAb}$ with wash solution. We investigated nucleophosmin (NPM1) expression by immunohistochemistry in CA tissue sections divided into two groups: BRAFV600E mutant CAs $(\mathrm{N}=7)$ and BRAF wild-type CAs $(\mathrm{N}=14)$, which included KRAS wild-type $(\mathrm{N}=6)$ or KRAS-mutated CAs $(\mathrm{N}=8)$. For the tissue evaluation of NPM expression, each slide was semiqualitatively scored - estimation was based on the nuclear staining intensity $(0-$ negative, 1 -weak, 2-strong) and cytoplasmic staining intensity ( 0 -negative, 1 -weak, 2 -strong), and the mean value was calculated. 


\subsection{Western Blot Analysis}

Cells were seeded in 6-well plates at a density of $1.5 \times 10^{5}$ cells per well and cultured for the indicated time period in the presence or absence of test agent. Cells were then lysed using RIPA buffer (25 mM Tris- $\mathrm{HCl}$ (pH 7.4), 1\% NP-40, 0.5\% Sodium Deoxycholate, $0.1 \% \mathrm{SDS}, 150 \mathrm{mM} \mathrm{NaCl}$ ) supplemented with protease and phosphatase inhibitor cocktails (Roche). A total of $50 \mu \mathrm{g}$ proteins was resolved on $10 \%$ or $12 \%$ SDS polyacrylamide gels and transferred onto PVDF membranes (Bio-Rad, Hercules, CA, USA). Membranes were blocked in either $5 \%$ bovine serum albumin (BSA) or non-fat milk prepared in TBST and probed with primary antibodies against NPM1 (1:4000) from Sigma-Aldrich and p-NPM1 (Thr199), c-Myc, p-c-Myc (Ser62), ENOPH1, PSPH, RanBP1, p-eIF4E (Ser209), p-ERK1/2 (Thr202/Tyr204), p-MEK1/2 (Ser217/221), p-AKT (Ser473), p-cRAF (Ser338) and $\alpha$-tubulin (1:1000) from Cell Signalling Technologies, overnight at $4{ }^{\circ} \mathrm{C}$. The next day, membranes were washed with TBST and probed with secondary antibody goat anti-mouse or goat anti-rabbit (Cell Signalling Technologies, 1:2000). Protein bands were visualized using Amersham ${ }^{\mathrm{TM}}$ ECL $^{\mathrm{TM}}$ Prime Western blotting Detection Reagent and Imagequant LASS 500 (GE Healthcare). Relative protein expression was analyzed by Quantity One 1-D Analysis Software (Bio-Rad, Hercules, CA, USA). Statistical analysis was performed by the two-tailed $t$-test, where a $p$-value of $<0.05$ was considered statistically significant.

Supplementary Materials: The following are available online at https:/ / www.mdpi.com/article/10 $.3390 /$ ijms22126174/s1.

Author Contributions: Conceptualization, M.S.; methodology, P.G., D.F.Č., T.G.; software, P.G., T.G.; validation, P.G., D.F.Č.; formal analysis, P.G., M.S., S.K.P.; investigation, P.G., M.S., S.K.P.; resources, M.S.; data curation, P.G., M.S.; writing-original draft preparation, P.G., M.S.; writing-review and editing, M.S., S.K.P.; visualization, P.G., M.S.; supervision, M.S.; project administration, M.S.; funding acquisition, M.S. All authors have read and agreed to the published version of the manuscript.

Funding: This research was funded by the Croatian Science Foundation grant number IP-2018-013900 and the University of Rijeka grant number uniri-biomed-18-76 1209 to Mirela Sedić.

Institutional Review Board Statement: Not applicable.

Informed Consent Statement: Not applicable.

Acknowledgments: We acknowledge the access to the research equipment owned by the University of Rijeka within the project RISK “Development of the University of Rijeka Campus laboratory research infrastructure" funded by the European Regional Development Fund.

Conflicts of Interest: The authors declare no conflict of interest.

\section{References}

1. Morris, V.K.; Bekaii-Saab, T. Improvements in Clinical Outcomes for BRAFV600E -Mutant Metastatic Colorectal Cancer. Clin. Cancer Res. 2020, 26, 4435-4441. [CrossRef] [PubMed]

2. Lai, E.; Pretta, A.; Impera, V.; Mariani, S.; Giampieri, R.; Casula, L.; Pusceddu, V.; Coni, P.; Fanni, D.; Puzzoni, M.; et al. BRAF-Mutant Colorectal Cancer, a Different Breed Evolving. Expert Rev. Mol. Diagn. 2018, 18, 499-512. [CrossRef]

3. Barras, D.; Missiaglia, E.; Wirapati, P.; Sieber, O.M.; Jorissen, R.N.; Love, C.; Molloy, P.L.; Jones, I.T.; McLaughlin, S.; Gibbs, P.; et al. BRAF V600E Mutant Colorectal Cancer Subtypes Based on Gene Expression. Clin Cancer Res 2017, 23, 104-115. [CrossRef] [PubMed]

4. Tian, S.; Simon, I.; Moreno, V.; Roepman, P.; Tabernero, J.; Snel, M.; van't Veer, L.; Salazar, R.; Bernards, R.; Capella, G. A Combined Oncogenic Pathway Signature of BRAF, KRAS and PI3KCA Mutation Improves Colorectal Cancer Classification and Cetuximab Treatment Prediction. Gut 2013, 62, 540-549. [CrossRef] [PubMed]

5. Popovici, V.; Budinska, E.; Tejpar, S.; Weinrich, S.; Estrella, H.; Hodgson, G.; Van Cutsem, E.; Xie, T.; Bosman, F.T.; Roth, A.D.; et al. Identification of a Poor-Prognosis BRAF-Mutant-like Population of Patients with Colon Cancer. J. Clin. Oncol. 2012, 30, 1288-1295. [CrossRef]

6. Vecchione, L.; Gambino, V.; Raaijmakers, J.; Schlicker, A.; Fumagalli, A.; Russo, M.; Villanueva, A.; Beerling, E.; Bartolini, A.; Mollevi, D.G.; et al. A Vulnerability of a Subset of Colon Cancers with Potential Clinical Utility. Cell 2016, 165, 317-330. [CrossRef]

7. Kim, I.-J.; Kang, H.C.; Jang, S.-G.; Kim, K.; Ahn, S.-A.; Yoon, H.-J.; Yoon, S.N.; Park, J.-G. Oligonucleotide Microarray Analysis of Distinct Gene Expression Patterns in Colorectal Cancer Tissues Harboring BRAF and K- Ras Mutations. Carcinogenesis 2006, 27, 392-404. [CrossRef] 
8. San Lucas, F.A.; Fowler, J.; Chang, K.; Kopetz, S.; Vilar, E.; Scheet, P. Cancer in silico Drug Discovery: A Systems Biology Tool for Identifying Candidate Drugs to Target Specific Molecular Tumor Subtypes. Mol. Cancer 2014, 13, 3230-3240. [CrossRef]

9. Mossmann, D.; Park, S.; Hall, M.N. MTOR Signalling and Cellular Metabolism Are Mutual Determinants in Cancer. Nat. Rev. Cancer 2018, 18, 744-757. [CrossRef] [PubMed]

10. Magaway, C.; Kim, E.; Jacinto, E. Targeting MTOR and Metabolism in Cancer: Lessons and Innovations. Cells 2019, 8, 1584. [CrossRef]

11. Fritsche-Guenther, R.; Zasada, C.; Mastrobuoni, G.; Royla, N.; Rainer, R.; Roßner, F.; Pietzke, M.; Klipp, E.; Sers, C.; Kempa, S. Alterations of MTOR Signaling Impact Metabolic Stress Resistance in Colorectal Carcinomas with BRAF and KRAS Mutations. Sci. Rep. 2018, 8, 9204. [CrossRef]

12. Coffee, E.M.; Faber, A.C.; Roper, J.; Sinnamon, M.J.; Goel, G.; Keung, L.; Wang, W.V.; Vecchione, L.; de Vriendt, V.; Weinstein, B.J.; et al. Concomitant BRAF and PI3K/MTOR Blockade Is Required for Effective Treatment of BRAFV600E Colorectal Cancer. Clin. Cancer Res. 2013, 19, 2688-2698. [CrossRef]

13. Zeller, K.I.; Haggerty, T.J.; Barrett, J.F.; Guo, Q.; Wonsey, D.R.; Dang, C.V. Characterization of Nucleophosmin (B23) as a Myc Target by Scanning Chromatin Immunoprecipitation. J. Biol. Chem. 2001, 276, 48285-48291. [CrossRef]

14. Marinkovic, D.; Marinkovic, T.; Kokai, E.; Barth, T.; Möller, P.; Wirth, T. Identification of Novel Myc Target Genes with a Potential Role in Lymphomagenesis. Nucleic Acids Res. 2004, 32, 5368-5378. [CrossRef]

15. Schmidt, E.V. The Role of C- Myc in Regulation of Translation Initiation. Oncogene 2004, 23, 3217-3221. [CrossRef]

16. Sun, L.; Song, L.; Wan, Q.; Wu, G.; Li, X.; Wang, Y.; Wang, J.; Liu, Z.; Zhong, X.; He, X.; et al. CMyc-Mediated Activation of Serine Biosynthesis Pathway Is Critical for Cancer Progression under Nutrient Deprivation Conditions. Cell Res. 2015, 25, 429-444. [CrossRef] [PubMed]

17. Hashimoto, N.; Nagano, H.; Tanaka, T. The Role of Tumor Suppressor P53 in Metabolism and Energy Regulation, and Its Implication in Cancer and Lifestyle-Related Diseases. Endocr. J. 2019, 66, 485-496. [CrossRef]

18. Pascal, L.E.; True, L.D.; Campbell, D.S.; Deutsch, E.W.; Risk, M.; Coleman, I.M.; Eichner, L.J.; Nelson, P.S.; Liu, A.Y. Correlation of MRNA and Protein Levels: Cell Type-Specific Gene Expression of Cluster Designation Antigens in the Prostate. BMC Genom. 2008, 9, 246. [CrossRef] [PubMed]

19. Tokuyama, Y.; Horn, H.F.; Kawamura, K.; Tarapore, P.; Fukasawa, K. Specific Phosphorylation of Nucleophosmin on Thr199 by Cyclin- Dependent Kinase 2-Cyclin E and Its Role in Centrosome Duplication. J. Biol. Chem. 2001, 276, 21529-21537. [CrossRef]

20. Wang, W.; Budhu, A.; Forgues, M.; Wang, X.W. Temporal and Spatial Control of Nucleophosmin by the Ran-Crm1 Complex in Centrosome Duplication. Nat. Cell Biol. 2005, 7, 823-830. [CrossRef] [PubMed]

21. Qi, W.; Shakalya, K.; Stejskal, A.; Goldman, A.; Beeck, S.; Cooke, L.; Mahadevan, D. NSC348884, a Nucleophosmin Inhibitor Disrupts Oligomer Formation and Induces Apoptosis in Human Cancer Cells. Oncogene 2008, 27, 4210-4220. [CrossRef]

22. Hu, M.-H.; Wang, Y.-Q.; Yu, Z.-Y.; Hu, L.-N.; Ou, T.-M.; Chen, S.-B.; Huang, Z.-S.; Tan, J.-H. Discovery of a New Four-Leaf Clover-Like Ligand as a Potent c-MYC Transcription Inhibitor Specifically Targeting the Promoter G-Quadruplex. J. Med. Chem. 2018, 61, 2447-2459. [CrossRef] [PubMed]

23. Rochlitz, C.F.; Heide, I.; Thiede, C.; Herrmann, R.; de Kant, E. Evidence for a Mutual Regulation of P53 and C-Myc Expression in Human Colorectal Cancer Metastases. Ann. Oncol. 1995, 6, 981-986. [CrossRef]

24. Frazier, M.W.; He, X.; Wang, J.; Gu, Z.; Cleveland, J.L.; Zambetti, G.P. Activation of C-Myc Gene Expression by Tumor-Derived P53 Mutants Requires a Discrete C-Terminal Domain. Mol. Cell Biol. 1998, 18, 3735-3743. [CrossRef] [PubMed]

25. Joyce, T.; Oikonomou, E.; Kosmidou, V.; Makrodouli, E.; Bantounas, I.; Avlonitis, S.; Zografos, G.; Pintzas, A. A Molecular Signature for Oncogenic BRAF in Human Colon Cancer Cells Is Revealed by Microarray Analysis. Curr. Cancer Drug Targets 2012, 12, 873-898. [CrossRef]

26. Klein, R.M.; Spofford, L.S.; Abel, E.V.; Ortiz, A.; Aplin, A.E. B-RAF Regulation of Rnd3 Participates in Actin Cytoskeletal and Focal Adhesion Organization. Mol. Biol. Cell 2008, 19, 498-508. [CrossRef]

27. Kim, M.H.; Kim, J.; Hong, H.; Lee, S.-H.; Lee, J.-K.; Jung, E.; Kim, J. Actin Remodeling Confers BRAF Inhibitor Resistance to Melanoma Cells through YAP/TAZ Activation. EMBO J. 2016, 35, 462-478. [CrossRef]

28. Hutton, J.E.; Wang, X.; Zimmerman, L.J.; Slebos, R.J.C.; Trenary, I.A.; Young, J.D.; Li, M.; Liebler, D.C. Oncogenic KRAS and BRAF Drive Metabolic Reprogramming in Colorectal Cancer. Mol. Cell Proteom. 2016, 15, 2924-2938. [CrossRef] [PubMed]

29. Sun, W.Y.; Kim, H.M.; Jung, W.-H.; Koo, J.S. Expression of Serine/Glycine Metabolism-Related Proteins Is Different According to the Thyroid Cancer Subtype. J. Transl. Med. 2016, 14, 168. [CrossRef]

30. Ross, K.C.; Andrews, A.J.; Marion, C.D.; Yen, T.J.; Bhattacharjee, V. Identification of the Serine Biosynthesis Pathway as a Critical Component of BRAF Inhibitor Resistance of Melanoma, Pancreatic, and Non-Small Cell Lung Cancer Cells. Mol. Cancer 2017, 16, 1596-1609. [CrossRef]

31. Liu, Y.; Zhang, F.; Zhang, X.-F.; Qi, L.-S.; Yang, L.; Guo, H.; Zhang, N. Expression of Nucleophosmin/NPM1 Correlates with Migration and Invasiveness of Colon Cancer Cells. J. Biomed. Sci. 2012, 19, 53. [CrossRef] [PubMed]

32. Wiesmann, N.; Gieringer, R.; Grus, F.; Brieger, J. Phosphoproteome Profiling Reveals Multifunctional Protein NPM1 as Part of the Irradiation Response of Tumor Cells. Transl. Oncol. 2019, 12, 308-319. [CrossRef]

33. Chartier, N.T.; Oddou, C.I.; Lainé, M.G.; Ducarouge, B.; Marie, C.A.; Block, M.R.; Jacquier-Sarlin, M.R. Cyclin-Dependent Kinase 2/Cyclin E Complex Is Involved in P120 Catenin (P120ctn)-Dependent Cell Growth Control: A New Role for P120ctn in Cancer. Cancer Res. 2007, 67, 9781-9790. [CrossRef] [PubMed] 
34. Harrison, L.E.; Bleiler, M.; Giardina, C. A Look into Centrosome Abnormalities in Colon Cancer Cells, How They Arise and How They Might Be Targeted Therapeutically. Biochem. Pharm. 2018, 147, 1-8. [CrossRef]

35. Zhang, M.S.; Arnaoutov, A.; Dasso, M. RanBP1 Governs Spindle Assembly by Defining Mitotic Ran-GTP Production. Dev. Cell 2014, 31, 393-404. [CrossRef]

36. Tedeschi, A.; Ciciarello, M.; Mangiacasale, R.; Roscioli, E.; Rensen, W.M.; Lavia, P. RANBP1 Localizes a Subset of Mitotic Regulatory Factors on Spindle Microtubules and Regulates Chromosome Segregation in Human Cells. J. Cell Sci. 2007, 120, 3748-3761. [CrossRef]

37. López, D.J.; Rodríguez, J.A.; Bañuelos, S. Nucleophosmin, a Multifunctional Nucleolar Organizer with a Role in DNA Repair. Biochim. Et Biophys. Acta (BBA) Proteins Proteom. 2020, 1868, 140532. [CrossRef] [PubMed]

38. Li, Z.; Boone, D.; Hann, S.R. Nucleophosmin Interacts Directly with C-Myc and Controls c-Myc-Induced Hyperproliferation and Transformation. Proc. Natl. Acad. Sci. USA 2008, 105, 18794-18799. [CrossRef] [PubMed]

39. Li, Z.; Hann, S.R. Nucleophosmin Is Essential for C-Myc Nucleolar Localization and c-Myc-Mediated RDNA Transcription. Oncogene 2013, 32, 1988-1994. [CrossRef] [PubMed]

40. Singleton, K.R.; Crawford, L.; Tsui, E.; Manchester, H.E.; Maertens, O.; Liu, X.; Liberti, M.V.; Magpusao, A.N.; Stein, E.M.; Tingley, J.P.; et al. Melanoma Therapeutic Strategies That Select against Resistance by Exploiting MYC-Driven Evolutionary Convergence. Cell Rep. 2017, 21, 2796-2812. [CrossRef]

41. Kopetz, S.; Desai, J.; Chan, E.; Hecht, J.R.; O’Dwyer, P.J.; Maru, D.; Morris, V.; Janku, F.; Dasari, A.; Chung, W.; et al. Phase II Pilot Study of Vemurafenib in Patients With Metastatic BRAF-Mutated Colorectal Cancer. J. Clin. Oncol. 2015, 33, 4032-4038. [CrossRef] [PubMed]

42. Kulshrestha, A.; Suman, S.; Ranjan, R. Network Analysis Reveals Potential Markers for Pediatric Adrenocortical Carcinoma. OTT 2016, 9, 4569-4581. [CrossRef] [PubMed] 